\title{
Serotonin Modulates Fast-Spiking Interneuron and Synchronous Activity in the Rat Prefrontal Cortex through 5- $\mathrm{HT}_{1 \mathrm{~A}}$ and 5- $\mathrm{HT}_{2 \mathrm{~A}}$ Receptors
}

\author{
M. Victoria Puig, ${ }^{1,2}$ Akiya Watakabe, ${ }^{3}$ Mika Ushimaru, ${ }^{1,4,5}$ Tetsuo Yamamori, ${ }^{3}$ and Yasuo Kawaguchi ${ }^{1,4,5}$ \\ ${ }^{1}$ Division of Cerebral Circuitry, National Institute for Physiological Sciences, Okazaki, Aichi 444-8787, Japan, ${ }^{2}$ The Picower Institute for Learning and \\ Memory, Department of Brain and Cognitive Sciences, Massachusetts Institute of Technology, Cambridge, Massachusetts 02139, ${ }^{3}$ Division of Brain Biology, \\ National Institute for Basic Biology, Okazaki, Aichi 444-8585, Japan, ${ }^{4}$ Japan Science and Technology Agency, Core Research for Evolutional Science \\ and Technology, Tokyo 102-0075, Japan, and 5Department of Physiological Sciences, Graduate University for Advanced Studies (SOKENDAI), Okazaki, \\ Aichi 444-8585, Japan
}

Alterations of the serotonergic system in the prefrontal cortex (PFC) are implicated in psychiatric disorders such as schizophrenia and depression. Although abnormal synchronous activity is observed in the PFC of these patients, little is known about the role of serotonin (5-HT) in cortical synchrony. We found that 5-HT, released by electrical stimulation of the dorsal raphe nucleus (DRN) in anesthetized rats, regulates the frequency and the amplitude of slow $(<2 \mathrm{~Hz})$ waves in the PFC via $5-\mathrm{HT}_{2 \mathrm{~A}}$ receptors $\left(5-\mathrm{HT}_{2 \mathrm{~A}} \mathrm{Rs}\right)$. 5- $\mathrm{HT}$ also modulates prefrontal gamma $(30-80 \mathrm{~Hz})$ rhythms through both $5-\mathrm{HT}_{1 \mathrm{~A}} \mathrm{Rs}$ and $5-\mathrm{HT}_{2 \mathrm{~A}} \mathrm{Rs}$, but not $5-\mathrm{HT}_{2 \mathrm{C}} \mathrm{Rs}$, inducing an overall decrease in the amplitude of gamma oscillations. Because fast-spiking interneurons (FSi) are involved in the generation of gamma waves, we examined

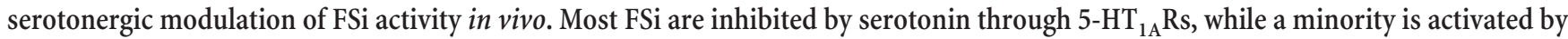
5- $\mathrm{HT}_{2 \mathrm{~A}} \mathrm{Rs}$, and not 5- $\mathrm{HT}_{2 \mathrm{C}}$ Rs. In situ hybridization histochemistry confirmed that distinct populations of FSi in the PFC express 5-HT ${ }_{1 \mathrm{~A}} \mathrm{Rs}$ and $5-\mathrm{HT}_{2 \mathrm{~A}} \mathrm{Rs}$, and that the number of FSi expressing $5-\mathrm{HT}_{2 \mathrm{C}} \mathrm{Rs}$ is negligible. We conclude that 5-HT exerts a potent control on slow and gamma oscillations in the PFC. On the one hand, it shapes the frequency and amplitude of slow waves through 5 -HT ${ }_{2 \mathrm{~A}} \mathrm{Rs}$ On the other hand, it finely tunes the amplitude of gamma oscillations through 5- $\mathrm{HT}_{2 \mathrm{~A}} \mathrm{R}$ - and $5-\mathrm{HT}_{1 \mathrm{~A}} \mathrm{R}$-expressing FSi, although it primarily downregulates gamma waves via the latter population. These results may provide insight into impaired serotonergic control of network activity in psychiatric illnesses such as schizophrenia and depression.

\section{Introduction}

The prefrontal cortex (PFC) is crucial for the control of important executive functions such as working memory and behavioral inhibition (Miller and Cohen, 2001). The synchronization of neuronal activity may be critical for the normal processing of these functions, since abnormal oscillatory activities in several frequency bands have been observed in the PFC of psychiatric patients (Başar and Güntekin, 2008), notably patients with schizophrenia (Spencer et al., 2003; Cho et al., 2006; Uhlhaas et al., 2008), who show clear cognitive impairment (Elvevåg and Goldberg, 2000; Harvey et al., 2001).

Specifically, a reduction in the synchronization of the slow and gamma bands has been reported in patients with schizophre-

Received July 13, 2009; revised Dec. 8, 2009; accepted Dec. 29, 2009.

This work was supported by grants-in-aid for Scientific Research from the Ministry of Education, Culture, Sports, Science, and Technology; the Japan Science and Technology Agency, Core Research for Evolutional Science and Technology; the Ministry of Health, Labour, and Welfare of Japan (Y.K.); and by the Japan Society for the Promotion of Science (M.V.P.). We thank M. Bosch, A. Gulledge, and S. Jhaveri for helpful comments on this manuscript; Y. Hirai and the Center for Experimental Animals for breeding and genotyping the transgenic line; and M. Saito, Y. Ito, S. Ohsawa, and M. Watanabe for technical assistance.

Correspondence should be addressed to either of the following at the above addresses: M. Victoria Puig, E-mail: mvpuig@mit.edu; or Yasuo Kawaguchi: E-mail: yasuo@nips.ac.jp.

DOI:10.1523/JNEUROSCI.3335-09.2010

Copyright $\odot 2010$ the authors $\quad 0270-6474 / 10 / 302211-12 \$ 15.00 / 0$ nia (Hoffmann et al., 2000; Spencer et al., 2003; Cho et al., 2006). Slow rhythms $(<2 \mathrm{~Hz})$ that occur during slow-wave sleep (SWS) are critical for memory consolidation (Stickgold, 2005; Marshall et al., 2006), and are generated intracortically from synchronized neuronal ensembles that oscillate between periods of activity (UP states) and silence (DOWN states) (Steriade et al., 1993). Gamma oscillations $(30-80 \mathrm{~Hz})$, on the other hand, provide a temporal structure for cognitive tasks such as attention and sensory processing (Singer, 1999; Howard et al., 2003; Ward, 2003), and are generated by networks of parvalbumin (PV)-expressing FSi (Whittington and Traub, 2003; Bartos et al., 2007). Interestingly, deficits in GABA synthesis in FSi of the PFC are found in schizophrenia patients (Lewis et al., 2005). Despite many atypical antipsychotic drugs and other psychiatric medication target serotonergic receptors (Meltzer, 1999), it is still poorly understood how 5-HT modulates FS and oscillatory activity in the PFC.

The PFC is densely innervated by serotonergic afferents that play a role in reversal learning and impulsivity (Robbins, 2005). However, the exact role of 5-HT in PFC function is largely unknown. The PFC is highly enriched in the 5-HT receptors 5- $\mathrm{HT}_{1 \mathrm{~A}}$ and 5- $\mathrm{HT}_{2 \mathrm{~A}}$ (Pompeiano et al., 1992, 1994): 5- $\mathrm{HT}_{1 \mathrm{~A}}$ Rs are inhibitory, and are involved in anxiety and learning (Heisler et al., 1998; Parks et al., 1998; Harder and Ridley, 2000), whereas 
$5-\mathrm{HT}_{2 \mathrm{~A}} \mathrm{Rs}$ are excitatory, and play a role in working memory (Williams et al., 2002). 5- $\mathrm{HT}_{1 \mathrm{~A}} \mathrm{Rs}$ and $5-\mathrm{HT}_{2 \mathrm{~A}} \mathrm{Rs}$ are expressed both in pyramidal neurons and GABAergic interneurons (Aznar et al., 2003; Santana et al., 2004; de Almeida and Mengod, 2007). Pyramidal cell discharge in vivo decreases or increases with stimulation of $5-\mathrm{HT}_{1 \mathrm{~A}}$ Rs or $5-\mathrm{HT}_{2 \mathrm{~A}} \mathrm{Rs}$, respectively (Puig et al., 2003, 2005; Amargós-Bosch et al., 2004). However, recording of interneurons in vivo is challenging, and the modulation that these receptors exert on the activity of FSi is not known.

We recently described the existence of two subpopulations of prefrontal FSi with different activity patterns during SWS: "early" FSi discharge during the first half of UP states, whereas "late" FSi fire later within UP states (Puig et al., 2008). We investigated how 5-HT modulates the activity of these two populations of FSi and the synchronization of slow and gamma oscillations in the PFC of anesthetized rats. Pharmacology and in situ hybridization histochemistry (ISH) was used to assess to involvement of $5-\mathrm{HT}_{1 \mathrm{~A}} \mathrm{Rs}$ and $5-\mathrm{HT}_{2 \mathrm{~A}} \mathrm{Rs}$ in this modulation.

\section{Materials and Methods}

These experiments were approved by the Animal Research Committee of the Okazaki National Research Institutes. All efforts were made to minimize both the suffering and number of animals used in this study.

Animals. Male Wistar rats (150-350 g) housed in a controlled environment (12 h light-dark cycles) were used. In some experiments VGAT (vesicular GABA transporter)-Venus line A transgenic rats were used to facilitate the identification of FSi: the majority of cortical GABAergic cells in this transgenic rat line are fluorescently labeled (Uematsu et al., 2008). VGAT-Venus rats were generated by Y. Yanagawa, M. Hirabayashi, and Y. Kawaguchi at the National Institute for Physiological Sciences (Okazaki, Japan) with pCS2-Venus provided by A. Miyawaki (RIKEN, Wako, Japan). VGAT-Venus rats are distributed from The National BioResource Project for the Rat in Japan (http://www.anim.med.kyoto-u.ac.jp: 80/nbr/default.aspx).

In vivo electrophysiology and electrical stimulations. Rats were anesthetized with chloral hydrate (initial dose $400 \mathrm{mg} / \mathrm{kg}$, intraperitoneally) and placed in a stereotaxic frame. Supplemental doses of anesthetic $(80 \mathrm{mg} /$ $\mathrm{kg}$, i.v.) were administered as needed (usually every $\sim 45 \mathrm{~min}$ ). Body temperature was maintained at $37^{\circ}$ throughout the experiment with a heating pad. All wound margins and points of contact between the animal and the stereotaxic apparatus were infiltrated with the anesthetic lidocaine, preventing all incidental pain. FSi single-unit activity $(n=40$; sampling rate $8 \mathrm{kHz}$ ) and local field potentials (LFPs; sampling rate 400 $\mathrm{Hz}$ ) were recorded from the same electrode placed in the secondary motor cortex (MOs, rostral medial agranular cortex, $\mathrm{AP}+3.2, \mathrm{~L} \pm 1.5$, DV -0.5 to $2 \mathrm{~mm}$ from bregma) of the PFC with Spike2 software (Cambridge Electronic Devices). Additionally, four FSi were recorded in the anterior cingulate and prelimbic regions $(\mathrm{AP}+3.2, \mathrm{~L} \pm 0.5, \mathrm{DV}-1$ to 3.5 $\mathrm{mm}$ ) of the medial PFC. Unit recordings and LFP signals were filtered online at $0.3-3 \mathrm{kHz}$ and $0.1-200 \mathrm{~Hz}$, respectively. Recordings were implemented with glass pipettes (15-50 M $\Omega$ ) filled with $2 \%$ Neurobiotin in $0.5 \mathrm{M} \mathrm{NaCl}$. Electrocorticogram (ECoG) activity (sampling rate $400 \mathrm{~Hz}$ ) was recorded on the left PFC (AP $+5.2, \mathrm{~L}-2, \mathrm{DV} 0 \mathrm{~mm})$ through a metal screw that was inserted through the skull, gently touching the dura mater, and was filtered online at $0.1-200 \mathrm{~Hz}$.

In addition, two stainless steel bipolar stimulating electrodes (California Fine Wire) were implanted in each animal: one in the right dorsal striatum (AP $+0.5, \mathrm{~L}+3, \mathrm{DV}-5 \mathrm{~mm})$, and another in the dorsal raphe nucleus (DRN, AP -7.8, L 0, DV $-6.5 \mathrm{~mm}$ ). Electrodes were lowered and cemented in place with cyanoacrylate glue and dental cement. Stimulations were monophasic square wave pulses of $0.2 \mathrm{~ms}$ and $0.1-2 \mathrm{~mA}$ at 1 or $100 \mathrm{~Hz}$.

In vivo pharmacology. WAY-100635 (5- $\mathrm{HT}_{1 \mathrm{~A}} \mathrm{R}$ antagonist; $20-80 \mu \mathrm{g} /$ $\mathrm{kg})$, ritanserin $\left(5-\mathrm{HT}_{2 \mathrm{~A} / 2 \mathrm{C}} \mathrm{R}\right.$ antagonist; $\left.0.5-2 \mathrm{mg} / \mathrm{kg}\right)$ and $\mathrm{SB}-242084$ (5- $\mathrm{HT}_{2 \mathrm{C}} \mathrm{R}$ antagonist; $0.5-2 \mathrm{mg} / \mathrm{kg}$ ) were obtained from Sigma/RBI. Dose ranges were selected according to those used in previous studies (Ugedo et al., 1989; Hajós et al., 2003; Puig et al., 2005; Boothman et al.,
2006). Drugs were diluted in saline and the $\mathrm{pH}$ was corrected. Aliquots were stored at $-20^{\circ} \mathrm{C}$ and thawed just before administration. All drugs were administered intravenously through the femoral vein in cumulative doses. Only one pharmacological experiment was performed in each animal.

Histology and in situ hybridization histochemistry. At the end of the recording session, neurons were stained with a juxtacellular injection of Neurobiotin, using $500 \mathrm{~ms}$ cycles of positive current pulses $(200 \mathrm{~ms}$ on/300 ms off, $<8$ nA) (Pinault, 1996; Puig et al., 2008). Two to four hours after the labelings, rats were perfused and the brains were removed and placed in fixative overnight. The brains were then sliced, and the position of the stimulating electrodes verified with Nissl staining. Frontal sections were processed for Neurobiotin (visualized with Alexa 350 avidin) and PV (visualized with Alexa 594 secondary antibody) immunoreactivity.

Double and triple ISH experiments were performed following protocols described previously (Watakabe et al., 2007). An example of the procedure used to quantify double-labeled cells is shown in supplemental Figure S1 (available at www.jneurosci.org as supplemental material). The probes for $5-\mathrm{HT}_{1 \mathrm{~A}} \mathrm{Rs}, 5-\mathrm{HT}_{2 \mathrm{~A}} \mathrm{Rs}$, and $5-\mathrm{HT}_{2 \mathrm{C}} \mathrm{Rs}$ were cloned by RT-PCR using the primers listed in supplemental Table S1, available at www.jneurosci.org as supplemental material. Two probes for $5-\mathrm{HT}_{1 \mathrm{~A}} \mathrm{Rs}$ and one probe for $5-\mathrm{HT}_{2 \mathrm{~A}} \mathrm{Rs}$ and $5-\mathrm{HT}_{2 \mathrm{C}}$ Rs were used.

Data and statistical analysis. The start and end of UP states were estimated by measuring changes in the $20-100 \mathrm{~Hz}$ component of the LFPs with MATLAB (MathWorks) following Mukovski et al., 2007 (a brief explanation is provided in Fig. 1 legend). The peaks of the power spectra (root mean square amplitude) were measured in Spike2. Spectrograms were constructed from raw power spectral density (PSD) (see Fig. 1) or from normalized PSD (in decibels) (see Figs. 2-4) in $100 \mathrm{~ms}$ bins and 4096 FFT using NeuroExplorer (Nex Technologies), and were smoothed with a Gaussian filter (10 ms sliding window). For each cell, we built phase histograms $\left(20^{\circ}\right.$ bin $)$ of spike-timing relative to gamma troughs. Gamma troughs were detected with the PTLEV script on the digitally filtered gamma band in Spike2. Firing probabilities were calculated by normalizing the number of spikes in each bin by the total number of cycles, and firing was considered modulated by the oscillation if $p<0.05$ using the Rayleigh test. From the phase histograms we computed the mean angle (preferred phase) and the depth of the modulation $(r)$, which was the length of the mean vector sum of all phase angles, normalized by the number of spikes/angle (Zar, 1999).

Responses of neurons to DRN electrical stimulation were characterized by measuring the delay, duration, and magnitude from peristimulus time histograms ( $2 \mathrm{~ms}$ bin width) following criteria described previously (Hajós et al., 1998; Puig et al., 2005). Firing rates during inhibitory/ excitatory responses are given as the percentage of firing rate during the response with respect to baseline ( $200 \mathrm{~ms}$ before the stimuli). Peristimulus histograms were built from 5 min epochs (except when stated) during baseline, and after the administration of the drug (always omitting the first minute after injection).

Data are expressed as mean \pm SD. Statistical significance was set at a 95\% confidence level (two-tailed).

\section{Results}

Serotonin modulates slow and gamma oscillations in the PFC We first investigated the modulation of cortical synchrony by endogenous 5-HT. The DRN was directly stimulated, inducing a massive release of 5-HT in the PFC (McQuade and Sharp, 1995; Gartside et al., 2000). Consequences of this release on slow and gamma oscillations recorded through LFPs were examined during anesthesia-induced SWS ("SWS-like states"). Experiments were performed after the administration of anesthetic to preclude effects of natural awakening.

LFP recordings were implemented in the secondary motor area (MOs) within the PFC: the MOs is densely innervated by serotonergic afferents of the DRN (Hoover and Vertes, 2007), and it does not project back to the raphe nuclei (Gabbott et al., 
A

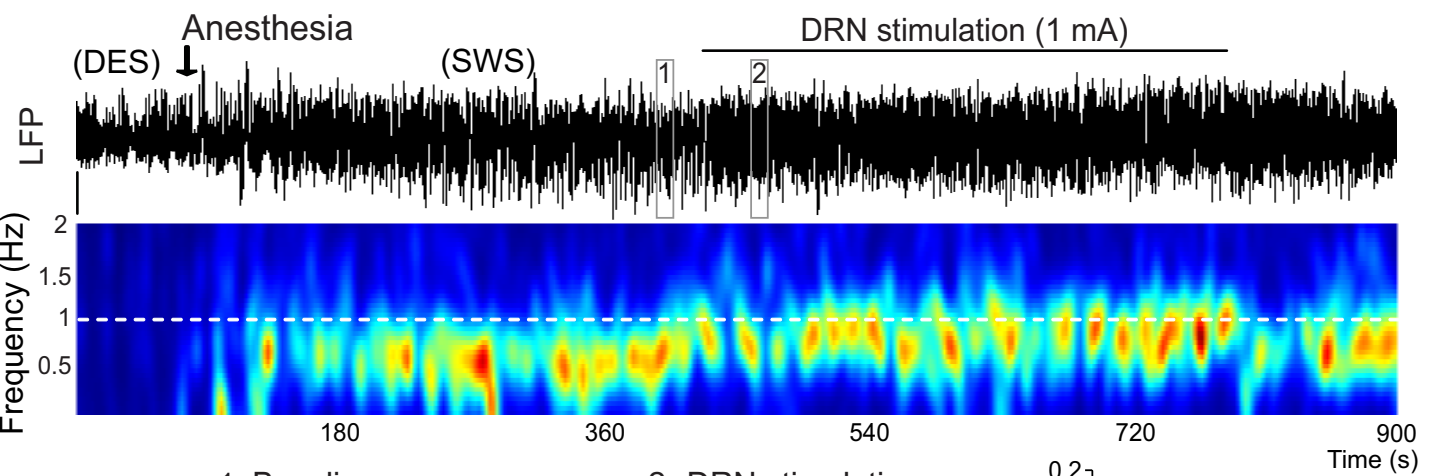

B

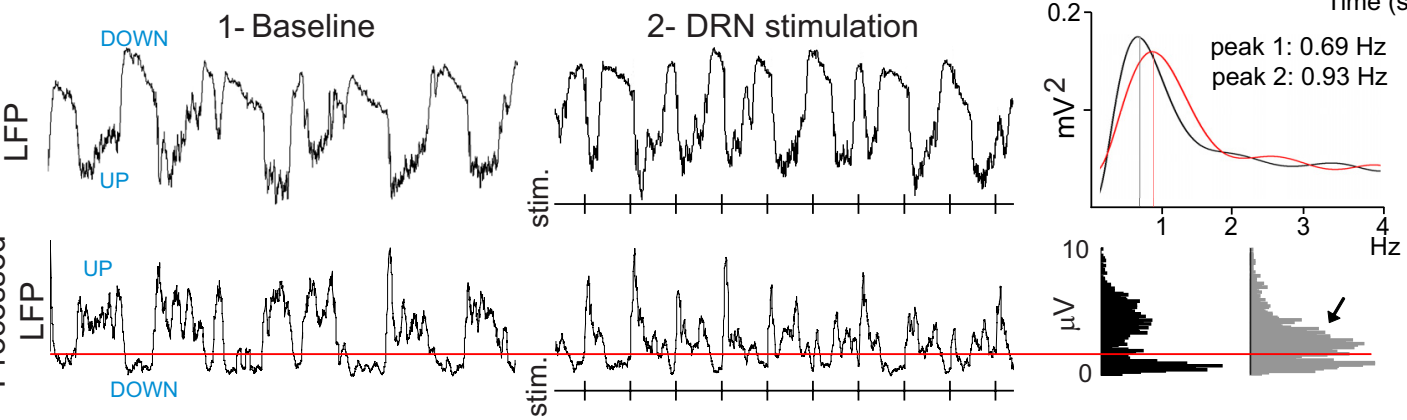

C
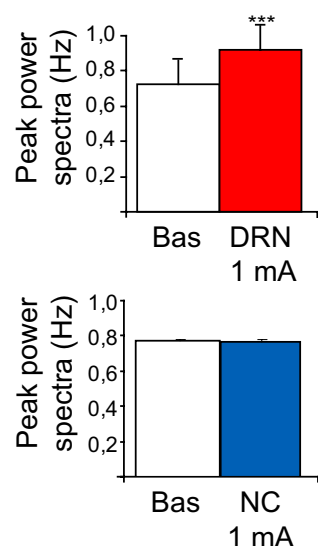
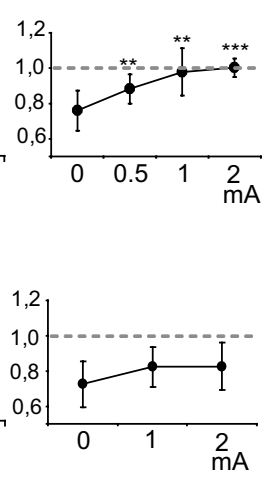

D
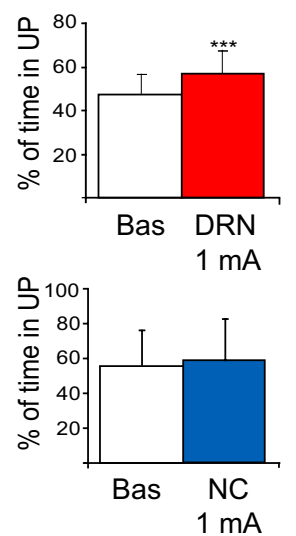

E
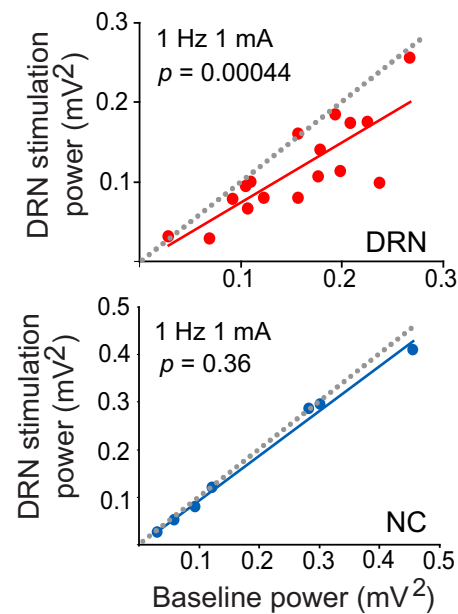

Figure 1. Low-frequency stimulation of the DRN $(1 \mathrm{~Hz})$ increases the frequency and reduces the amplitude of cortical slow waves. $\boldsymbol{A}$, LFP trace and corresponding spectrogram of 15 min of recording. Note that during the stimulations slow waves decrease in amplitude and increase in frequency toward the frequency of stimulation (white line in spectrogram). The spectrogram is raw PSD smoothed with a Gaussian filter. Vertical bar: $0.5 \mathrm{mV}$. DES, Desynchronization epoch (or wake-like state). SWS, Slow-wave sleep epoch (or SWS-like state). Red is maximum and blue is minimum signal in all figures. $\boldsymbol{B}$, Top, Detail of 10 s of LFP signal during SWS-like (box 1 in $\boldsymbol{A}$ ) and DRN stimulation segments (box 2 in $\boldsymbol{A}$; vertical lines correspond to times of stimulation). Power spectra for 1 min segments that contain the 10 s traces in boxes 1 and 2 are shown on the far right. Bottom, LFPs were processed off-line for an accurate measure of UP-state duration. Briefly, the $20-100 \mathrm{~Hz}$ component of the LFP was digitally extracted and the SD of 10 ms sliding windows computed. Histograms of processed LFPs displayed two peaks corresponding to UP and DOWN potentials (far right). A threshold was set (red line) to discriminate UP states (Mukovski et al., 2007). Note the increase in UP-state potentials during the stimulations (arrow). $C$, D, The peaks of the power spectra and the percentage of time the LFPs spent in UP states were significantly increased during DRN stimulations at $1 \mathrm{~mA}$ ( $n=21$ rats), indicating an increase in the frequency of slow waves. Augmenting the intensity of the stimulations up to $2 \mathrm{~mA}$ reliably imposed a frequency of $1 \mathrm{~Hz}(\boldsymbol{C}$, right). These effects were not observed in negative control rats (NC; $n=7)$, even increasing the intensity of the stimulations up to $2 \mathrm{~mA} .{ }^{* *} p<0.01,{ }^{* * *} p<0.001$. Data are mean \pm SD. $\boldsymbol{E}$, Effects of DRN simulation on the baseline power of slow waves (comparison of 30 s epochs before and during stimulations). Each dot depicts one experiment. Only one experiment was performed per animal.

2005); thus, we avoided a confounding antidromic activation of cortico-raphe pyramidal axon collaterals.

\section{Low-frequency stimulation of the DRN}

Serotonergic neurons in the DRN discharge slowly and rhythmically at $\sim 1$ spike/s under chloral hydrate anesthesia (Celada et al., 2001). We stimulated electrically the DRN at $1 \mathrm{~Hz}$ to synchronize the spiking of serotonergic neurons and induce a massive release of 5-HT in projection areas, including the PFC.

Stimulation of the DRN at $1 \mathrm{~mA}$ consistently and reversibly increased the frequency of slow waves in the PFC (Fig. 1A): UP/ DOWN-state cycles appeared more irregular and of shorter duration (Fig. $1 B$ ), indicating that 5 -HT was altering cortical synchrony. The peak of the LFP power spectra (the predominant frequency) significantly increased from $0.74 \pm 0.1$ to $0.94 \pm 0.1$ $\mathrm{Hz}$ (Fig. $1 C$, left) $\left(p=3.7 \times 10^{-5}, n=21\right.$ rats, paired $t$ test $)$, suggesting that the stimulations were imposing their frequency onto the cortical network. Increasing the release of 5-HT into the cortex by augmenting the intensity of the stimulations up to $2 \mathrm{~mA}$ reliably imposed a frequency of $1 \mathrm{~Hz}$ on slow oscillations $(n=10$ rats, paired $t$ test) (Fig. $1 C$, right).

Stimulations delivered during DOWN states systematically promoted UP states within $29.6 \pm 7.4 \mathrm{~ms}$ (average of $10, n=10$ 
rats) (Fig. $1 B$ ). This latency is consistent with that reported previously for serotonergic neurons antidromically activated from the PFC (24 $\pm 1 \mathrm{~ms}$ ) (Puig et al., 2005), which suggests a monosynaptic effect. These results reveal that the activity of serotonergic neurons in the DRN may directly modulate the frequency of cortical slow waves by promoting the initiation of UP states. During the stimulations, as the number of UP states increased (from $23 \pm 8$ to $28 \pm 5$ in $30 \mathrm{~s}, p=0.0043$ ), the percentage of time that the LFPs spent in UP states [52.7\% $(15.8 \pm 5.1 \mathrm{~s})]$ was greater than during baseline $[43.7 \%(13.1 \pm 4.4 \mathrm{~s})]\left(p=4 \times 10^{-5}, n=\right.$ 15 rats, paired $t$ test) (Fig. $1 D$ ).

Seven additional rats, with stimulating electrodes implanted outside the DRN (location shown in supplemental Fig. S2, available at www.jneurosci.org as supplemental material), were used as negative controls (NC). In these animals, no significant changes were detected in the peaks of the LFP power spectra between baseline and stimulation periods [ $30 \mathrm{~s}$ epochs, $n=7$ rats, paired $t$ test (from $0.78 \pm 0$ to $0.78 \pm 0.006 \mathrm{~Hz}, p=0.42$ )] (Fig. $1 C)$, even augmenting the intensity of the stimulations up to 2 $\mathrm{mA}$ ( $n=5$ rats) (Fig. $1 C$, right). The percentage of time spent in UP states did not change either [from $55 \%(16.5 \pm 6.3 \mathrm{~s})$ to 58.7\% (17.1 $\pm 7.2 \mathrm{~s}), p=0.36$ ] (Fig. 1D).

We then analyzed the effects of DRN stimulation on the power (RMS amplitude) of low-frequency and gamma oscillations (comparison between $30 \mathrm{~s}$ epochs during baseline and stimulations). The power of slow waves markedly decreased during the stimulations ( $p=4.4 \times 10^{-4}, n=17$ rats), an effect not observed in NC animals ( $n=7$ rats, $p=0.36$, paired $t$ test) (Fig. $1 E$ ). However, DRN stimulation did not alter the power of the gamma band ( $p=0.88, n=17$ rats; data not shown).

\section{High-frequency stimulation of the DRN}

During the process of awakening, slow waves increase in frequency, decrease in amplitude, and eventually disappear by reducing the presence of DOWN-state hyperpolarizing potentials. As a result, during wakefulness, LFPs are in a permanent depolarized "UP" state, also called "desynchronized" state (Steriade et al., 1993, 2001). An example of this is seen in Figure $1 A$ (marked as "DES"), where slow waves are absent at the start of the recording before the animal is deeply anesthetized. Our results suggest that 5-HT was "wakening" the cortex, although the slow and short-duration stimulations used might have allowed a rapid reuptake of 5-HT. We explored this idea further by stimulating the DRN strongly at $100 \mathrm{~Hz}$ for $0.5 \mathrm{~s}(0.4 \mathrm{~mA})$. Quantification of the power of slow and gamma oscillations before and after stimulations at $100 \mathrm{~Hz}$ showed that both bands were significantly decreased (comparison of $10 \mathrm{~s}$ periods, $n=7$ rats) (Fig. $2 A$ ). The stimulations completely suppressed cortical slow waves for several seconds (Fig. $2 B$ ), confirming previous results (Dringenberg and Vanderwolf, 1997), which support a role of 5-HT in the transition between sleep and alert brain states (Portas et al., 2000).

Collectively, these observations show that 5-HT modulates both slow and gamma oscillatory activities in the PFC during SWS-like states. Specifically, 5-HT regulates the frequency of slow waves by promoting UP-state onset. Furthermore, stimulations of the DRN at $1 \mathrm{~Hz}$ induce an increase in the frequency of slow oscillations and a decrease in the power that resembles the natural process of awakening. This effect is largely enhanced after stimulations at $100 \mathrm{~Hz}$, which also implicates 5-HT in the downregulation of gamma waves.
A

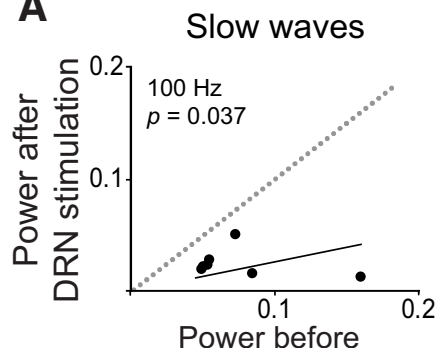

DRN stimulation $\left(\mathrm{mV}^{2}\right)$
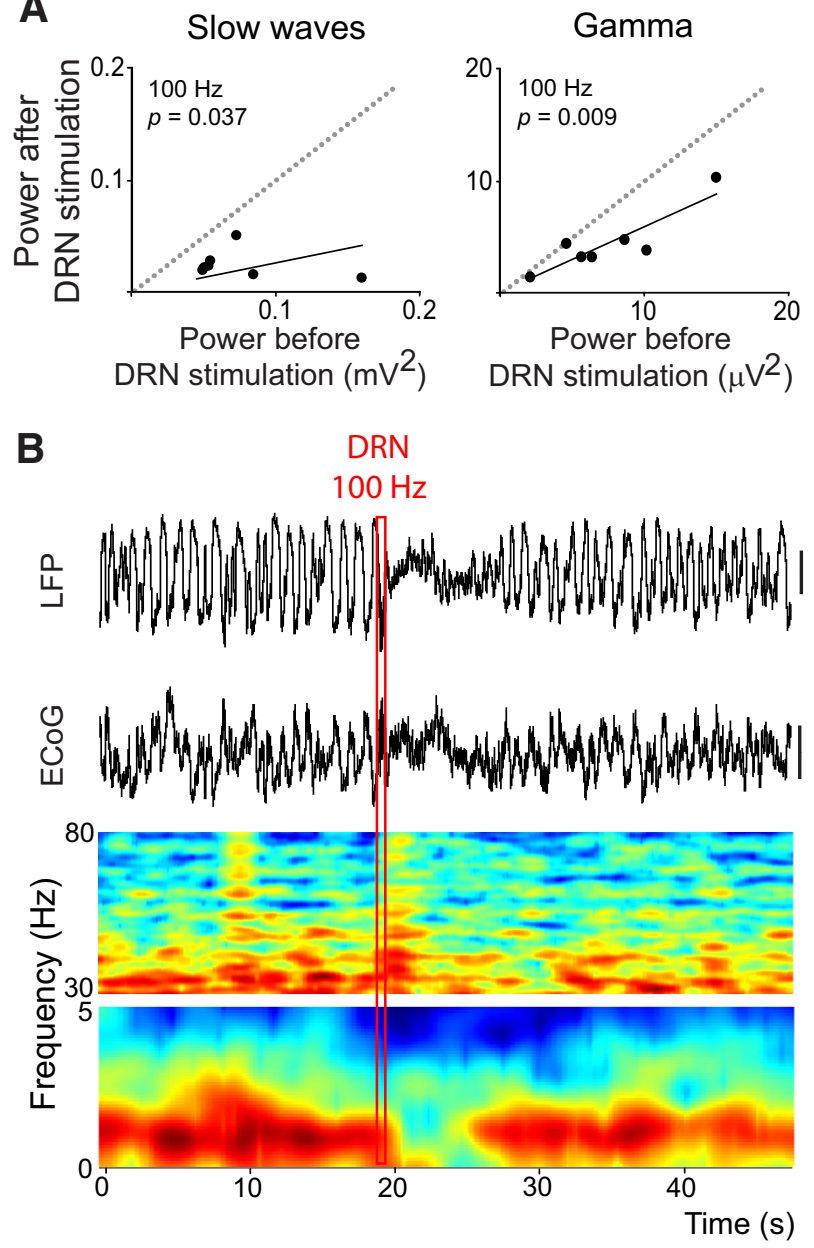

Figure 2. High-frequency stimulation of the DRN $(100 \mathrm{~Hz})$ strongly desynchronizes cortical slow waves and reduces gamma power. $\boldsymbol{A}$, Stimulations of the DRN at $100 \mathrm{~Hz}$ ( $400 \mu \mathrm{A}$ for $0.5 \mathrm{~s}$ ) decrease the power of both slow and gamma oscillations in the LFP signal (comparison of $10 \mathrm{~s}$ epochs before and after the stimulations; $n=7$ rats). $\boldsymbol{B}$, The stimulation rapidly eliminates slow waves for several seconds in both the LFP and ECOG signals (top). Time-frequency analysis of the LFP reveals the disappearance of the slow-wave band and a reduction of the power of gamma waves (bottom). Spectrograms are normalized PSDs (in decibels), smoothed with a Gaussian filter. The red rectangle depicts the time of the stimulation and contains the stimulus artifacts in all the signals. Vertical bars are $0.5 \mathrm{mV}$.

\section{Serotonin modulates slow and gamma oscillations via 5-HT ${ }_{1 \mathrm{~A}}$ Rs and 5- $\mathrm{HT}_{2 \mathrm{~A}}$ Rs}

In the PFC, $5-\mathrm{HT}_{1 \mathrm{~A}} \mathrm{Rs}$ and $5-\mathrm{HT}_{2 \mathrm{~A}} \mathrm{Rs}$ are the most abundantly expressed serotonergic receptors: $5-\mathrm{HT}_{1 \mathrm{~A}} \mathrm{Rs}$ are inhibitory (coupled to $\mathrm{G}_{\mathrm{i} / 0}$ ) and $5-\mathrm{HT}_{2 \mathrm{~A}}$ Rs are excitatory (coupled to $\mathrm{G}_{\mathrm{q}}$ ). We examined the effects of a pharmacological blockade of these receptors on the power of slow and gamma waves in the PFC. The DRN was not stimulated during these experiments.

Intravenous administration of the selective $5-\mathrm{HT}_{1 \mathrm{~A}} \mathrm{R}$ antagonist WAY-100635 (WAY) did not change the power of lowfrequency oscillations ( $n=9$ rats, $40 \mu \mathrm{g} / \mathrm{kg}$, paired $t$ test) (Fig. $3 A$ ). In contrast, blockade of $5-\mathrm{HT}_{2 \mathrm{~A} / 2 \mathrm{C}} \mathrm{R}$ by ritanserin (RIT) dramatically decreased slow-wave power $(n=7$ rats, $1 \mathrm{mg} / \mathrm{kg})$ (Fig. 3A). RIT has a higher affinity for $5-\mathrm{HT}_{2 \mathrm{~A}} \mathrm{Rs}$ than for 5- $\mathrm{HT}_{2 \mathrm{C}} \mathrm{Rs}$ (Hoyer, 1988; Jenck et al., 1993). However, the responses mediated by these two receptors cannot be easily discriminated using RIT. Previous studies have shown that the $5-\mathrm{HT}_{2 \mathrm{C}} \mathrm{R}$ antagonist SB-242084 (SB) has 100-fold more selectivity for $5-\mathrm{HT}_{2 \mathrm{C}} \mathrm{Rs}$ than for $5-\mathrm{HT}_{2 \mathrm{~A}} \mathrm{Rs}$ (Kennett et al., 1997), and 


\section{A Slow waves}
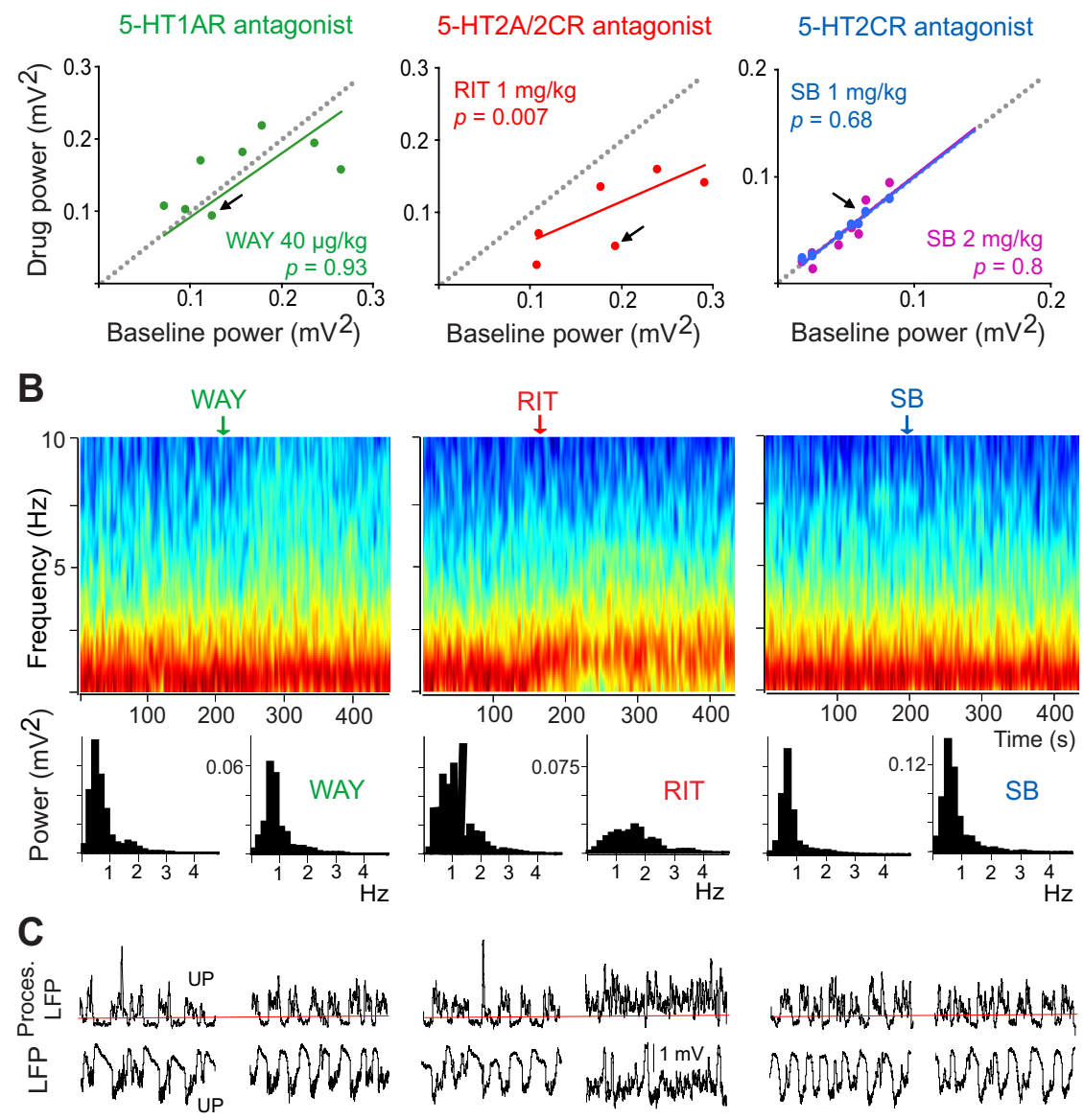

Figure 3. Modulation of slow oscillations by $5-\mathrm{HT}_{2 \mathrm{~A}} \mathrm{Rs}$. $\boldsymbol{A}$, Scatter plots of the effects of WAY-100635 (WAY), ritanserin (RIT), and SB-242084 (SB) on the power of slow oscillations (comparison of 30 s epochs before and after drug injection). Arrows point to the examples shown in $\boldsymbol{B}$ and $\boldsymbol{C}$. $\boldsymbol{B}$, Examples of the effects of WAY, RIT, and SB on the power of slow waves by time-frequency analysis (normalized PSDs in decibels), and corresponding quantification of the power. Vertical arrows point to the start of the injections. RIT markedly decreases the power of slow waves. Since SB does not alter slow-wave power, the effects of RIT are likely mediated by $5-\mathrm{HT}_{2 \mathrm{~A}} \mathrm{Rs}$. $\boldsymbol{C}$, Representative $10 \mathrm{~s}$ traces of the LFPs from the examples shown in $\boldsymbol{B}$. Analysis of UP and DOWN cycles reveals that RIT reduces the number, duration, and amplitude of DOWN states, markedly augmenting UP-state potentials. This leads to a desynchronization of slow waves. Proces. LFP, LFP processed as in Figure $1 B$. Red line indicates the calculated threshold between UP and DOWN states.

that at a dose of $1 \mathrm{mg} / \mathrm{kg}$ it has no significant occupancy of $5-\mathrm{HT}_{2 \mathrm{~A}} \mathrm{Rs}$ in the rat brain in vivo (Boothman et al., 2006). We therefore used SB to investigate the involvement of $5-\mathrm{HT}_{2 \mathrm{C}}$ Rs in the responses mediated by RIT. SB did not alter the power of slow oscillations ( $n=8$ rats) either at 1 or $2 \mathrm{mg} / \mathrm{kg}$ (Fig. $3 A$ ), suggesting a role for $5-\mathrm{HT}_{2 \mathrm{~A}} \mathrm{Rs}$ in RIT-induced responses. Figure $3 B$ provides examples (marked with arrows in Fig. $3 A$ ) of the effects of WAY, RIT, and SB on the slow band using time-frequency analysis and corresponding quantification of the power. A detailed examination of the effects of these antagonists on UP/DOWN cycles revealed that RIT desynchronizes slow oscillations by reducing the number, duration, and amplitude of DOWN states, resulting in a marked increase of UP-state potentials. WAY and SB did not have any overt effect on UP and DOWN states (Fig. 3C).

We then examined the effects of the antagonists on the gamma band. WAY increased the power of gamma oscillations $(n=9$ rats; paired $t$ test), whereas RIT decreased it ( $n=7$ rats, $1 \mathrm{mg} / \mathrm{kg}$ ). Again, SB did not have any effect ( $n=8$ rats, 1 or $2 \mathrm{mg} / \mathrm{kg}$ ) (Fig. $4 A$ ). Representative examples are shown in Figure $4 B$ (marked with arrows in Fig. $4 A$ ).
Altogether, these data suggest that the modulation exerted by 5-HT on slow oscillatory activity is primarily mediated by $5-\mathrm{HT}_{2 \mathrm{~A}} \mathrm{Rs}$. They also suggest that both $5-\mathrm{HT}_{1 \mathrm{~A}} \mathrm{Rs}$ and $5-\mathrm{HT}_{2 \mathrm{~A}} \mathrm{Rs}$, but not $5-\mathrm{HT}_{2 \mathrm{C}} \mathrm{Rs}$, are involved in the regulation of gamma rhythms during SWS.

\section{Serotonin induces $5-\mathrm{HT}_{1 \mathrm{~A}} \mathrm{R}$-mediated inhibitions and 5- $\mathrm{HT}_{2 \mathrm{~A}} \mathrm{R}$-mediated activations in "early" and "late" FSi in vivo}

Since FSi are involved in the generation of gamma oscillations, we asked whether 5-HT regulates the activity of FSi in the PFC through $5-\mathrm{HT}_{1 \mathrm{~A}} \mathrm{Rs}$ and $5-\mathrm{HT}_{2 \mathrm{~A}} \mathrm{Rs}$. To facilitate the identification of FSi, unit recordings paired with juxtacellular injections of Neurobiotin were implemented in VGAT-Venus transgenic rats. Electrophysiological and immunohistochemical identification of the FSi presented in this study is provided in a previous paper (Puig et al., 2008). Serotonergic modulation of FSi activity was assessed by electrical stimulation of the DRN at $1 \mathrm{~Hz}$. Importantly, the level of anesthesia was manipulated so that the ECoG looked similar to that in SWS states ("SWS-like states," induced by deep anesthesia) or awakening ("waking-like states" or "desynchronized states," induced by light anesthesia, where slow waves are absent) (Fig. 1A).

The effects of DRN stimulation were assessed in 31 FSi during SWS-like states. The stimulations induced transient inhibitions in the majority of FSi recorded (19 of $31,61.3 \%$ ) (Table 1 ). Cessation of firing was evident only when the DRN was stimulated during UP states, since cells do not discharge during hyperpolarizing DOWN states (Steriade et al., 1993) (Fig. 5A, top). Additionally, 3 units were activated (9.7\%) (Fig. 5B, top) and 2 more cells exhibited mixed responses, with activations preceded by short-duration inhibitions (6.5\%) (supplemental Fig. S3, available at www.jneurosci.org as supplemental material). Another 7 neurons were not affected by DRN stimulation $(22.5 \%$; data not shown).

For 13 additional FSi the effects of DRN stimulation were assessed during waking-like states, epochs of light anesthesia that occur spontaneously during the transition between anesthetized states and alertness. During these epochs animals did not show any sign of consciousness despite having desynchronized LFPs. Immediately after the experiments, rats were given a supplemental dose of anesthetic that generated slow oscillations within $\sim 10-20$ s (Fig. 1 A). During waking-like states, eight FSi ( 8 of 13, $61.5 \%$ ) were inhibited by DRN stimulation, four units were excited $(30.8 \%)$ and another displayed a mixed response $(7.7 \%$; Table 1). A map of the stimulation sites in the DRN that elicited inhibitions, excitations, mixed responses, and no responses in prefrontal FSi is shown in supplemental Figure S2 (available at 
www.jneurosci.org as supplemental material). We did not observe any obvious pattern of distribution for these sites within the DRN.

We have previously reported that neocortical FSi can be divided in two major populations according to their pattern of activity during SWS-like states: FSi that discharge on the first half of UP states were named "early" FSi, and FSi spiking during the second half of UP states were called "late" FSi. Remarkably, "early" FSi decrease considerably their discharge frequency during waking-like epochs, whereas "late" FSi dramatically increase it, suggesting that the latter subpopulation may be responsible for generating the gamma oscillations associated with cognitive processing during wakefulness.

We classified all the neurons used in this study in the "early" or "late" patterns according to their spike timing during UP states and the difference in firing rate between SWS-like and waking-like states (Puig et al., 2008). Table 1 summarizes the number of neurons of each population that showed the distinct types of response evoked by DRN stimulation during the two states. Population analysis confirmed that "early" FSi decreased spiking during waking-like epochs with respect to SWSlike epochs, whereas "late" FSi tripled it. Clearly, a larger number of "early" FSi was recorded, which suggests that neurons with this pattern of activity might be more active than "late" FSi during SWS states. Additionally, although most FSi in both populations were inhibited by DRN stimulations, "late" FSi showed a higher proportion of units that were activated. Interestingly, during waking-like states the proportion of activations increased in both populations. Inhibitions and excitations were very similar between "early" and "late" FSi ( $p>0.4$ for delay, duration, and firing rate during the responses, unpaired $t$ test; Table 2 ).

\section{In vivo pharmacology}

Systemic administration of WAY $(20-80 \mu \mathrm{g} / \mathrm{kg}$, i.v. $)$ fully reversed six of the nine inhibitions tested (Fig. $5 A$, bottom), and partially blocked the other three (from an initial duration of $126 \pm 37 \mathrm{~ms}$ to $35 \pm 15 \mathrm{~ms}$ ), suggesting that all the responses were (fully or partially) mediated by $5-\mathrm{HT}_{1 \mathrm{~A}} \mathrm{Rs}$. On the other hand, RIT $(0.5-2 \mathrm{mg} / \mathrm{kg}$, i.v.) and SB (0.5-2 $\mathrm{mg} / \mathrm{kg}$, i.v.) were used to test for the involvement of $5-\mathrm{HT}_{2 \mathrm{~A}} \mathrm{Rs}$ and $5-\mathrm{HT}_{2 \mathrm{C}} \mathrm{Rs}$ in the excitatory responses, respectively. RIT blocked excitation in the three units tested (Fig. $5 \mathrm{~B}$, bottom): firing rates during activation dropped from $435 \pm 190 \%$ to $164 \pm 47 \%$ of baseline. On the other hand, administration of SB did not reverse the activation in two FSi excited by DRN stimulation (up to $2 \mathrm{mg} / \mathrm{kg}$; from $417 \pm 83 \%$ to $482 \pm 98 \%$ of baseline activity) (Fig. $5 C$ ). These results suggest that FSi in the PFC are predominately activated through $5-\mathrm{HT}_{2 \mathrm{~A}} \mathrm{Rs}$ and not $5-\mathrm{HT}_{2 \mathrm{C}} \mathrm{Rs}$. Finally, we tried to characterize pharmacologically the only three mixed responses recorded. In two of these neurons the inhibition was blocked by WAY (supplemental Fig. S3, available at www.jneurosci.org as supplemental material); for the third one, the activation was
Table 1. Number of "early" and "late" FSi that exhibit the distinct responses evoked by the stimulation of the DRN during SWS-like and waking-like states

\begin{tabular}{lccc}
\hline & Early & Late & All \\
\hline SWS-like states & & & \\
$\quad$ Inhibition (count) & 12 & 6 & 19 \\
$\quad$ Excitation (count) & 1 & 2 & 3 \\
Mixed (count) & 1 & 1 & 2 \\
$\quad$ No effect (count) & 4 & 1 & 7 \\
Total (count) & 18 & 10 & 31 \\
$\quad$ Spikes/s during UP states & $5.2 \pm 5$ & $4.9 \pm 4$ & $5.2 \pm 5$ \\
Waking-like states & & & \\
Inhibition (count) & 5 & 2 & 8 \\
$\quad$ Excitation (count) & 2 & 1 & 4 \\
Mixed (count) & 1 & 0 & 1 \\
No effect (count) & 0 & 0 & 0 \\
Total (count) & 8 & 3 & 13 \\
Spikes/s & $1.9 \pm 3$ & $16 \pm 16^{* * *}$ & $5.6 \pm 10$ \\
All (count) & 26 & 13 & 44 \\
\hline "All" colmin
\end{tabular}

"All" column includes units that could not be classified in either pattern. Data are mean \pm SD. ${ }^{* * *} p=0.0004$.

blocked by RIT. This suggests that $5-\mathrm{HT}_{1 \mathrm{~A}} \mathrm{Rs}$ and $5-\mathrm{HT}_{2 \mathrm{~A} / 2 \mathrm{C}} \mathrm{Rs}$ could be functionally coexpressed in a small population of FSi.

In summary, the in vivo electrophysiological data show that 5-HT can inhibit, activate, or induce mixed responses in subpopulations of FSi of the PFC via $5-\mathrm{HT}_{1 \mathrm{~A}}$ Rs and $5-\mathrm{HT}_{2 \mathrm{~A}} \mathrm{Rs}$. Yet, a predominance of $5-\mathrm{HT}_{1 \mathrm{~A}} \mathrm{R}$-mediated inhibitions both during SWS-like and waking-like states indicates that overall 5-HT exerts a potent inhibitory drive on cortical FSi activity. However, because "late" FSi are proportionally more activated by DRN stimulation than "early" FSi, 5-HT might selectively promote FSi 
A
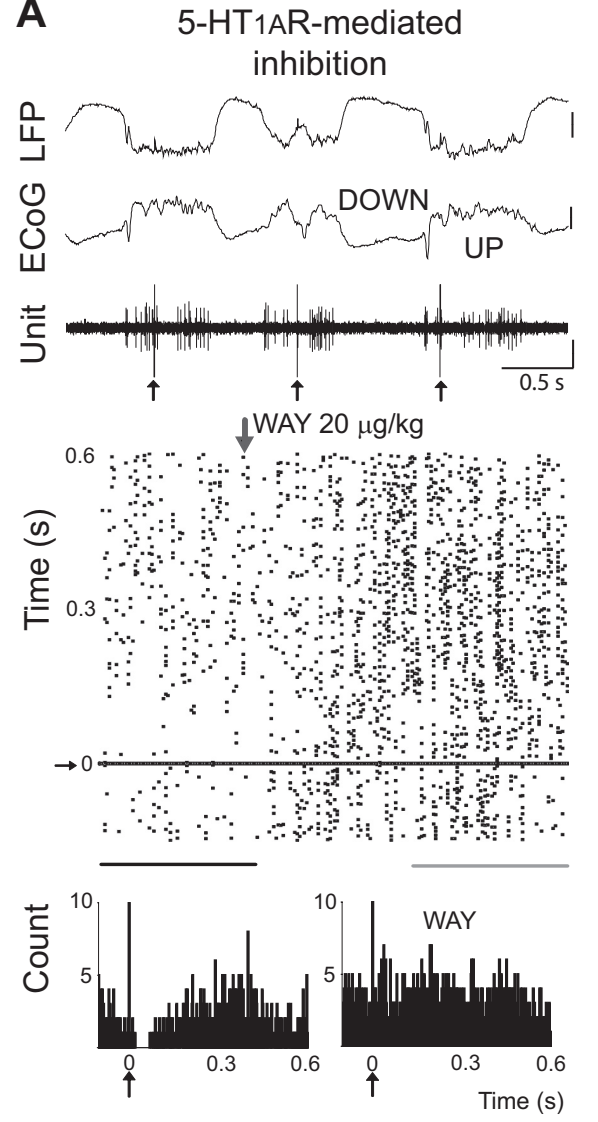

\section{B 5 -HT2A/2CR-mediated excitation}
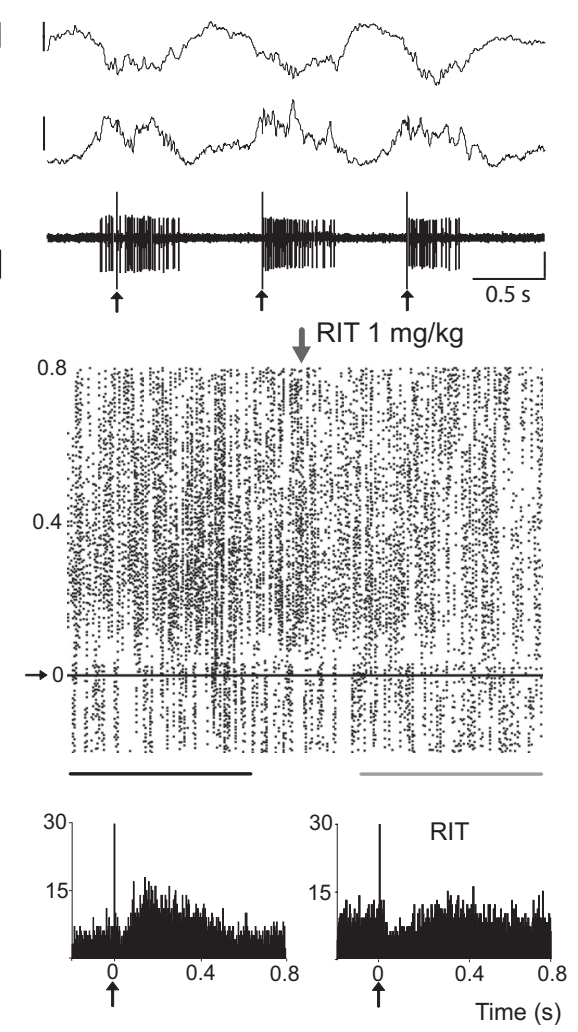

C

Putative 5-HT2AR-mediated excitation
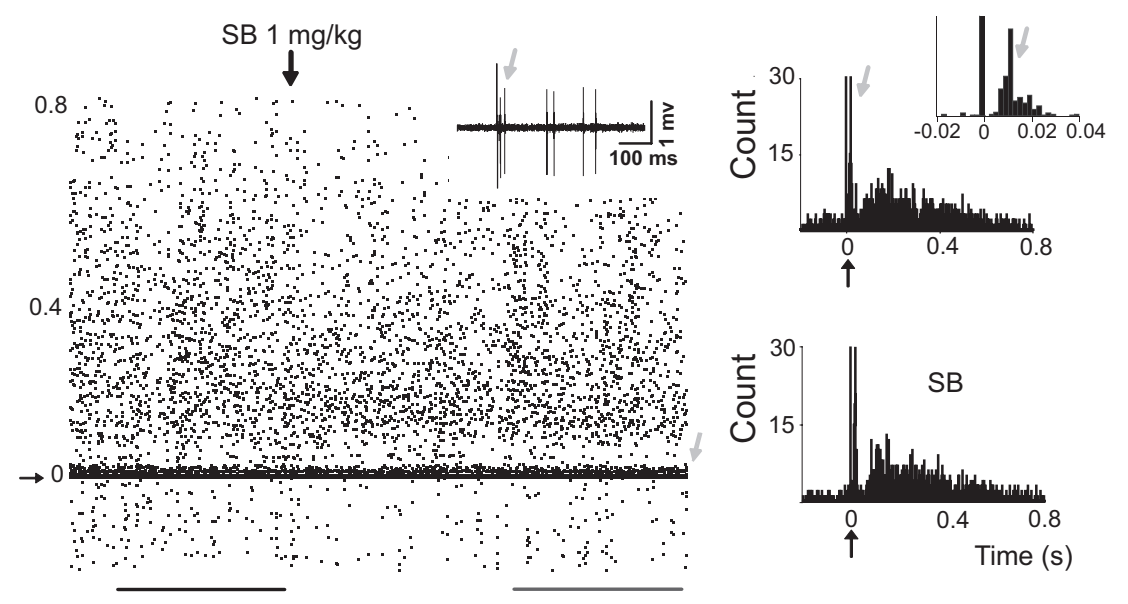

Figure 5. Opposite modulation of $\mathrm{FSi}$ activity in vivo through $5-\mathrm{HT}_{1 \mathrm{~A}} \mathrm{Rs}$ and $5-\mathrm{HT} \mathrm{T}_{2 \mathrm{As}} \mathrm{R} . \boldsymbol{A}, \boldsymbol{B}$, Top, DRN stimulation $(1 \mathrm{~Hz})$ delivered during UP states induced transient inactivations in many FSi recorded (left), while a subset of FSi were activated (right). Vertical bar is $0.5 \mathrm{mV}$. Bottom, Raster plots and corresponding peristimulus histograms of the units shown above. Inhibitions were mediated by $5-\mathrm{HT}_{1 \mathrm{~A}} \mathrm{Rs}$ and activations by $5-\mathrm{HT}_{2 \mathrm{~A} / 2 \mathrm{C}} \mathrm{Rs}$. Zero is time of DRN stimulation. Peristimulus histograms were built during baseline (black lines under raster plots) and after the administration of WAY or RIT (gray lines). Lines are $5 \mathrm{~min}$ epochs. Vertical arrows point to the start of the injections. Small vertical arrows point to stimulus artifacts. Both units were confirmed to be PV positive. C, Raster plot and peristimulus histogram of a FSi activated by DRN stimulation during baseline (black line), and after the administration of SB (gray line). SB failed to reverse the activation (up to $2 \mathrm{mg} / \mathrm{kg}$ ), suggesting that it was $5-\mathrm{HT}_{2 \mathrm{~A}} \mathrm{R}$-mediated. Lines are 3 min epochs. Inset, Note the presence of a short-delay short-duration excitation (light gray arrows) with variable latencies. This cell was one of the few FSi recorded in the medial PFC (see Materials and Methods). Because the medial PFC projects densely to the DRN, this response may be due to feedforward inputs from cortico-raphe pyramidal neurons activated antidromically from the DRN (Puig et al., 2008). Alternatively, a glutamatergic response induced by 5 - HT/glutamate corelease from serotonergic terminals should also be considered (Varga et al., 2009). This unit was confirmed to be PV positive.

activity on the second half of UP states during SWS. More importantly, the percentage of cells excited by DRN stimulation during waking-like states was higher than during SWS-like states $(31 \%$ vs $10 \%$ ), which suggests that 5 -HT may indeed increase the spiking of a substantial number of FSi during alertness.

\section{Effects of 5-HT ${ }_{1 \mathrm{~A}} \mathrm{R}$ and $5-\mathrm{HT}_{2 \mathrm{~A} / 2 \mathrm{C}} \mathrm{R}$ antagonists on the baseline firing rate of FSi and their synchronization to gamma waves}

Next, we asked whether 5-HT regulates the gamma band by modulating the activity of $\mathrm{FSi}$ expressing $5-\mathrm{HT}_{1 \mathrm{~A}} \mathrm{Rs}$ and $5-\mathrm{HT}_{2 \mathrm{~A}} \mathrm{Rs}$. To gain insight on this, we first examined the effects of the $5-\mathrm{HT}_{1 \mathrm{~A}} \mathrm{R}$ and $5-\mathrm{HT}_{2 \mathrm{~A} / 2 \mathrm{C}} \mathrm{R}$ antagonists WAY and RIT on the activity of FSi measured during UP states, in SWS-like periods where the DRN was not stimulated. The baseline firing rate of FSi was independent of direction of serotonergic modulation of activity (mean firing rate was $7.64 \pm 5.37$ spikes/s for neurons inhibited, $n=8$, and $7.95 \pm 5.18$ spikes/s for neurons excited by DRN stimulation, $n=5 ; p=0.92$ ).

In 7 of 8 units that showed $5-\mathrm{HT}_{1 \mathrm{~A}} \mathrm{R}$ mediated inhibitions after DRN stimulation (6 "early" and 2 "late" FSi) a consistent increase of spiking was noted after the administration of WAY (baseline firing rate was $7.64 \pm 5.37 \mathrm{~Hz}$ and $12.35 \pm 8.78 \mathrm{~Hz}$ after WAY injection; $p=0.04, n=8$, paired $t$ test) (Fig. 6A). Therefore, WAY increased overall activity in a subset of FSi, likely those expressing $5-\mathrm{HT}_{1 \mathrm{~A}} \mathrm{Rs}$, which could account for the increase in amplitude of gamma oscillations observed after the administration of this drug (Fig. 4).

More diverse effects of RIT were noted on the activity of FSi that exhibited putative $5-\mathrm{HT}_{2 \mathrm{~A}} \mathrm{R}$-mediated activations after DRN stimulation. Spiking in one unit was clearly diminished (an "early" FSi) whereas in the other two units it was augmented (both cells displayed "late" pattern) (Fig. 6A). Thus, the decrease in the power of gamma waves observed after the injection of RIT (Fig. 4) cannot be explained purely by a decrease in the activity of $5-\mathrm{HT}_{2 \mathrm{~A}} \mathrm{R}$-expressing FSi. Rather, the change in firing rate of the neurons was more dependent on their pattern of activity during waking-like states ("early" FSi decrease and "late" FSi increase spiking), since RIT systematically desynchronizes cortical slow waves.

We therefore reasoned that 5-HT could be regulating the amplitude of cortical gamma waves by modulating the way FSi are synchronized to the local network. To 
test this we compared the preferred phase angles at which individual FSi fired during gamma cycles, and their depth of modulation, before and after administration of WAY or RIT. The depth of modulation $(r)$ is a quantification of the strength at which a neuron is coupled to a specific oscillation: $r$ can range from 0 (no coupling; i.e., spikes are uniformly distributed across all phases within a cycle) to 1 (best coupling; i.e., spikes are locked to the same phase of the oscillation). Blockade of $5-\mathrm{HT}_{1 \mathrm{~A}}$ Rs with WAY did not change the preferred phase at which FSi fired within gamma cycles ( $p>0.05, n=6$, Watson-Williams test), but significantly increased the depth of their modulation $(p=0.016$, $n=6$ ) [Fig. $6 B$ (top), $C$ ]. This indicates that WAY sharpened the coupling of $5-\mathrm{HT}_{1 \mathrm{~A}} \mathrm{R}$-expressing FSi to gamma waves, possibly reflecting an increase in their synchronization to the gamma network. In contrast, blockade of $5-\mathrm{HT}_{2 \mathrm{~A} / 2 \mathrm{C}} \mathrm{Rs}$ by RIT uncoupled the two "late" units to gamma cycles, despite the increase in their firing rate, and left unaltered the coupling of the neuron that showed decreased activity $(n=3)$ [Fig. $6 B$ (bottom), $C$ ].

Together, these observations suggest that 5-HT regulates the amplitude of cortical gamma waves by modulating the strength at which $5-\mathrm{HT}_{1 \mathrm{~A}} \mathrm{R}$ - and $5-\mathrm{HT}_{2 \mathrm{~A}} \mathrm{R}$ expressing FSi are synchronized to gamma oscillations.

\section{5-HT ${ }_{1 \mathrm{~A}} \mathrm{Rs}, 5-\mathrm{HT}_{2 \mathrm{~A}} \mathrm{Rs}$, and 5- $\mathrm{HT}_{2 \mathrm{C}} \mathrm{Rs}$ are differently expressed in parvalbumin-positive cells in the PFC} Finally, we quantified the expression of 5- $\mathrm{HT}_{1 \mathrm{~A}} \mathrm{Rs}, 5-\mathrm{HT}_{2 \mathrm{~A}} \mathrm{Rs}$, and $5-\mathrm{HT}_{2 \mathrm{C}} \mathrm{Rs}$ in $\mathrm{FSi}$ of the rat MOs by performing double and triple fluorescence (ISH) of mRNAs for these receptors and for parvalbumin (PV), a calcium-binding protein that is selectively expressed in FSi (Kawaguchi and Kubota, 1997; Uematsu et al., 2008).

mRNAs for $5-\mathrm{HT}_{1 \mathrm{~A}} \mathrm{Rs}$ and $5-\mathrm{HT}_{2 \mathrm{~A}} \mathrm{Rs}$ were found in $35.8 \pm 7.4 \%$ and $23.3 \pm$ $6.4 \%$ of PV-expressing neurons (average of all layers), respectively (Fig. $7 A, B$ ). However, almost all $5-\mathrm{HT}_{2 \mathrm{C}} \mathrm{R}$-positive cells appeared to be PV negative. Only $2.0 \pm 1.4 \%$ of PV-positive cells showed expression of $5-\mathrm{HT}_{2} \mathrm{R}$ mRNA, and in all cases the level of the signal was very low (Fig. 7C). To corroborate these latter results, a double ISH of $5-\mathrm{HT}_{2 \mathrm{C}} \mathrm{R}$ mRNA and the pyramidal cell marker VGluT1 (vesicular glutamate transporter type 1) was carried out. Most 5- $\mathrm{HT}_{2 \mathrm{C}} \mathrm{R}$-positive neurons coexpressed the VGluT1 transcript, demonstrating that $5-\mathrm{HT}_{2 \mathrm{C}} \mathrm{Rs}$ are expressed primarily in excitatory neurons (Fig. 7D).

In examining the laminar distribution of these receptors, we found a tendency for PV- and 5- $\mathrm{HT}_{1 \mathrm{~A}} \mathrm{R}$-expressing cells to localize in layers $2-5$, with a preference for layer 5 ( $42 \%$ in layers $2 / 3$ vs $52 \%$ in layer 5 ), and few cells in the upper part of layer $6(6 \%)$ (supplemental Fig. S1, available at www.jneurosci.org as supplemental material). One-way ANOVA revealed a significant effect of layer in the distribution of neurons expressing PV and $5-\mathrm{HT}_{1 \mathrm{~A}} \mathrm{Rs}$ when comparing percentage of double-labeled cells across layers $\left(F_{(2,6)}=12.7, p<0.01\right)$. The percentage of PV-and $5-\mathrm{HT}_{2 \mathrm{~A}} \mathrm{R}$ mRNA-coexpressing cells was also significantly different across layers (36\% in layers $2 / 3,60 \%$ in layer 5 , and $4 \%$ in layer 6; $\left.F_{(2,6)}=19.3, p<0.001\right)$. Thus, PV-positive neurons
Table 2. Characteristics of the inhibitory and excitatory responses evoked by the stimulation of the DRN in "early" and "late" FSi during SWS-like states

\begin{tabular}{lccc}
\hline & Early & Late & All \\
\hline Inhibitions & & & \\
$\quad$ Sample size $(n)$ & 12 & 6 & 19 \\
$\quad$ Delay (ms) & $22 \pm 8$ & $22 \pm 8$ & $22 \pm 7$ \\
$\quad$ Duration (ms) & $111 \pm 91$ & $105 \pm 29$ & $107 \pm 75$ \\
$\quad$ \% of prestimulus firing rate during the inhibition* & $11 \pm 11$ & $19 \pm 10$ & $14 \pm 11$ \\
Excitations & & & \\
$\quad$ Sample size ( $n$ ) & 1 & 2 & 3 \\
Delay (ms) & 61 & $85 \pm 5$ & $77 \pm 14$ \\
$\quad$ Duration (ms) & 205 & $357 \pm 10$ & $306 \pm 88$ \\
\% of prestimulus firing rate during the excitation* & 253 & $273 \pm 78$ & $266 \pm 57$ \\
\hline
\end{tabular}

"All" column includes units that could not be classified in either pattern. *Prestimulus firing rates are mean firing rates during the $200 \mathrm{~ms}$ before the stimuli. Data are mean \pm SD.

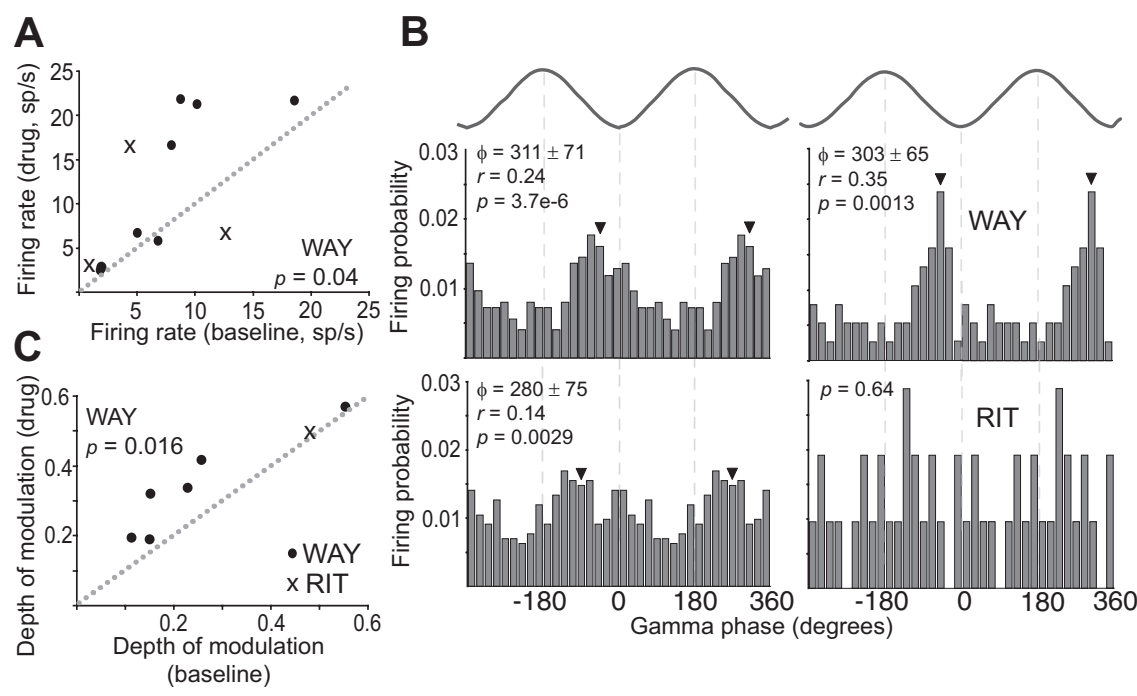

Figure 6. Effects of 5- $\mathrm{HT}_{1 \mathrm{~A}} \mathrm{R}$ and $5-\mathrm{HT}_{2 \mathrm{~A} / 2 \mathrm{C}} \mathrm{R}$ antagonists on FSi activity and synchronization to gamma waves. $\boldsymbol{A}$, Scatter plot of firing rates before and after injection of WAY (filled circles) and RIT (crosses). Firing rates were measured from UP states detected 1 min segments. $\boldsymbol{B}$, Examples of the effects of WAY and RIT on the coupling of two distinct FSi to gamma waves. Shown are firing distributions around gamma troughs before and after drug injection. Two gamma cycles are shown for clarity. Top, WAY did not change the preferred firing phase ( $\Phi$; marked with an arrowhead), but increased the depth of the modulation $(r)$, "sharpening" the distribution. Bottom, RIT uncoupled this unit to gamma waves ( $p>0.05)$. $p$ values are from the Rayleigh Test. Bin $=20^{\circ}$. C, Scatter plot of the depth of modulation to gamma waves before and after the administration of WAY (filled circles) or RIT (crosses). RIT uncoupled 2 of the 3 units tested, for which a depth of modulation could not be computed.

expressing $5-\mathrm{HT}_{1 \mathrm{~A}} \mathrm{R}$ or $5-\mathrm{HT}_{2 \mathrm{~A}} \mathrm{R}$ mRNAs are enriched in layer 5 and much less abundant in layer 6 . A quantification of the percentage of double labeled neurons within layers $2 / 3,5$, and 6 is provided in Table 3.

Recent studies have shown that $\sim 60 \%$ of pyramidal neurons in the MOs express 5- $\mathrm{HT}_{1 \mathrm{~A}}$ Rs or 5- $\mathrm{HT}_{2 \mathrm{~A}} \mathrm{Rs}$ (Santana et al., 2004), and that many of these actually coexpress both receptors (Amargós-Bosch et al., 2004). Interestingly, our electrophysiological results suggested that the small population of FSi that display mixed responses following DRN stimulation may coexpress both receptors. To examine this, we performed triple ISH of 5- $\mathrm{HT}_{1 \mathrm{~A}} \mathrm{R}, 5-\mathrm{HT}_{2 \mathrm{~A}} \mathrm{R}$, and PV mRNAs. We observed extensive colocalization of $5-\mathrm{HT}_{1 \mathrm{~A}} \mathrm{R}$ and $5-\mathrm{HT}_{2 \mathrm{~A}} \mathrm{R}$ mRNAs in many cells, consistent with earlier reports (Martín-Ruiz et al., 2001; Amargós-Bosch et al., 2004). However, only few of these cells also contained PV mRNA (supplemental Fig. S3, available at www. jneurosci.org as supplemental material).

Overall, the ISH data indicate that, unlike pyramidal neurons, very few FSi in the MOs express $5-\mathrm{HT}_{2 \mathrm{C}} \mathrm{Rs}$, and that $5-\mathrm{HT}_{1 \mathrm{~A}} \mathrm{Rs}$ and $5-\mathrm{HT}_{2 \mathrm{~A}} \mathrm{Rs}$ are largely distributed in distinct subpopulations 

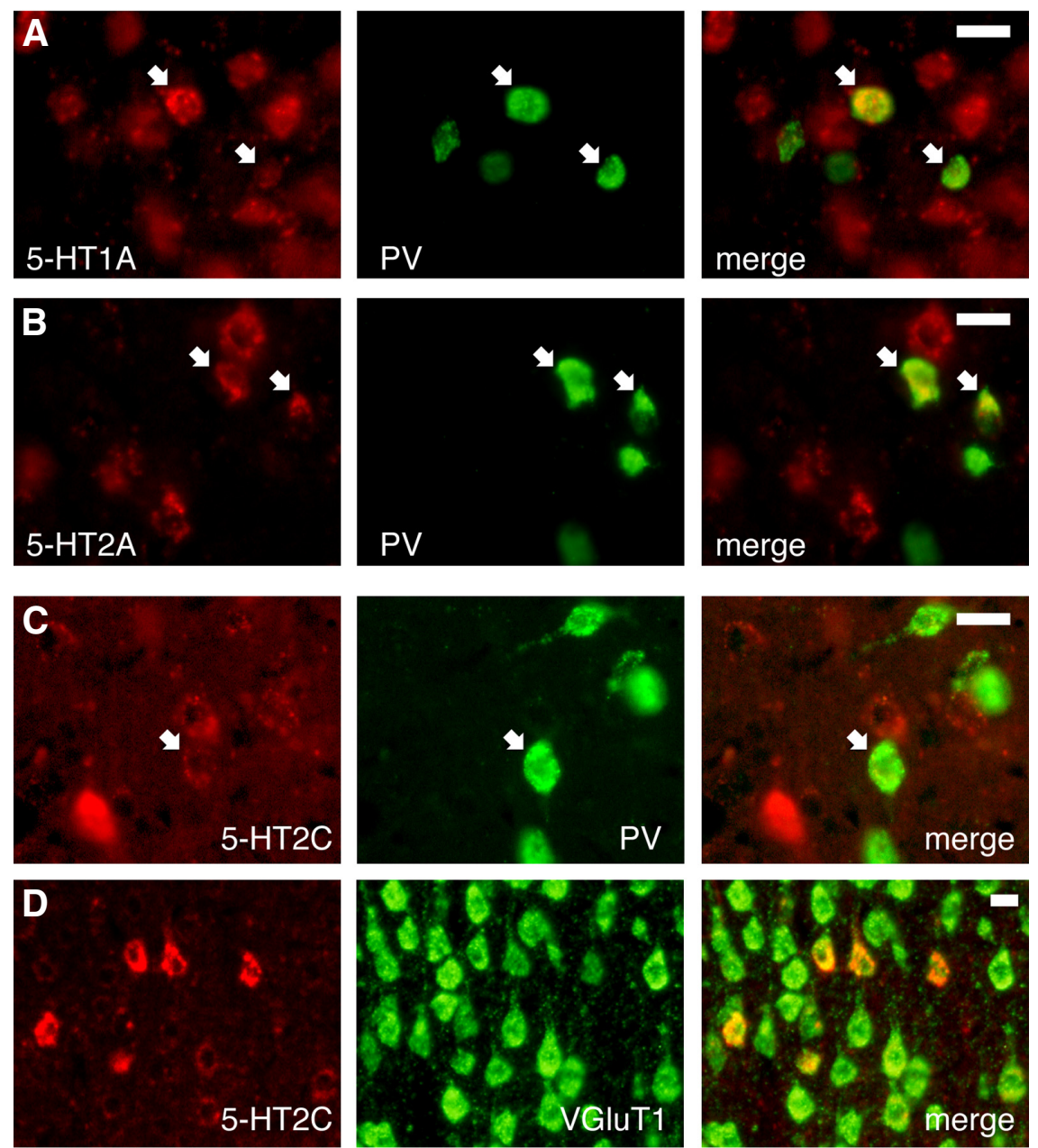

Figure 7. Expression of 5-HT ${ }_{1 A} \mathrm{R}, 5-\mathrm{HT}_{2 \mathrm{~A}} \mathrm{R}$, and 5-HT $2 \mathrm{C}$ mRNAs in PV-positive neurons. $\boldsymbol{A}-\boldsymbol{C}$, Colocalization of the FSi marker parvalbumin (PV) with $5-\mathrm{HT}_{1 \mathrm{~A}} \mathrm{R}(\boldsymbol{A}), 5-\mathrm{HT}_{2 \mathrm{~A}} \mathrm{R}(\boldsymbol{B})$, and $5-\mathrm{HT}_{2 \mathrm{C}} \mathrm{R}(\boldsymbol{C})$ mRNAs by double ISH (MOs, $n=3$ rats each). Note a higher background on the latter ISH, consequence of a weak expression of the signal. $\boldsymbol{D}$, Colocalization of $5-\mathrm{HT}_{2 C} \mathrm{R}$ mRNAs with the pyramidal neuron marker VGluT1. Examples of double-labeled neurons are marked with white arrows. Scale bars are $20 \mu \mathrm{m}$.

Serotonin modulates the frequency, amplitude, and synchronization of slow oscillations in the PFC

Electrical stimulation of the DRN at physiological rates, by augmenting the release of endogenous 5-HT in cortical regions (Gartside et al., 2000), consistently increase the frequency and reduce the amplitude of slow waves in the PFC during anesthesia-induced SWS. These effects are triggered by a rapid promotion of UP states, with latencies $(\sim 30 \mathrm{~ms})$ consistent with the conduction velocity of serotonergic axons projecting to the PFC ( $\sim 24 \mathrm{~ms})$ (Puig et al., 2005). Thus, serotonergic neurons in the DRN may directly regulate the frequency and amplitude of slow waves during SWS. Importantly, we cannot rule out the involvement of glutamatergic raphe-cortex inputs: many neurons in the DRN express VGluT3 (Gras et al., 2002; Jackson et al., 2009; Varga et al., 2009), and there is evidence of a fast $(\sim 10$ ms) AMPA/NMDA-mediated synaptic transmission in the hippocampus involving 5-HT/VGluT3-containing terminals from the MRN (Varga et al., 2009). This transmission, however, is too fast to explain the shifts from DOWN to UP states described here.

Since UP states reflect a membrane depolarization of neurons (Steriade et al., 1993), an excitatory receptor might mediate the increase of UP-state potentials observed during the stimulations. Despite we cannot preclude the involvement of glutamate, it is likely that cortical $5-\mathrm{HT}_{2 \mathrm{~A}} \mathrm{Rs}$ are largely responsible for these effects. $5-\mathrm{HT}_{2 \mathrm{~A}} \mathrm{Rs}$ are abundantly expressed by

Table 3. Quantification of PV-positive neurons expressing 5- $\mathrm{HT}_{1 \mathrm{~A}} \mathrm{R}$ and $5-\mathrm{HT}_{2 \mathrm{~A}} \mathrm{R}$ mRNAs within layers of the MOs by double ISH

\begin{tabular}{lll}
\hline & PV mRNA & \\
\cline { 2 - 3 } $5-\mathrm{HT}_{1 \mathrm{~A}}$ mRNAs & $5-\mathrm{HT}_{2 \mathrm{~A}}$ mRNA \\
\hline Layer 2/3 (\%) & $46 \pm 14$ & $20 \pm 11$ \\
Layer 5 (\%) & $35 \pm 10$ & $29 \pm 8$ \\
Layer 6 (\%) & $12 \pm 11$ & $13 \pm 23$ \\
All layers (\%) & $36 \pm 7$ & $23 \pm 6$ \\
\hline
\end{tabular}

Data are mean \pm SD.

of FSi. Moreover, both $5-\mathrm{HT}_{1 \mathrm{~A}} \mathrm{R}$ - and $5-\mathrm{HT}_{2 \mathrm{~A}} \mathrm{R}$-expressing $\mathrm{FSi}$ are more abundant in layer 5 , where $\sim 30 \%$ of FSi express each of the receptor subtypes (Table 3 ).

\section{Discussion}

The main findings of this study are as follows: (1) 5-HT modulates the frequency, amplitude, and synchronization of slow waves; (2) 5-HT primarily downregulates FSi activity via $5-\mathrm{HT}_{1 \mathrm{~A}} \mathrm{Rs}$; and (3) 5 -HT regulates gamma oscillations through $5-\mathrm{HT}_{1 \mathrm{~A}} \mathrm{Rs}$ and $5-\mathrm{HT}_{2 \mathrm{~A}} \mathrm{Rs}$. We propose that the modulation of gamma rhythms is implemented through distinct subpopulations of FSi expressing $5-\mathrm{HT}_{1 \mathrm{~A}} \mathrm{Rs}$ and $5-\mathrm{HT}_{2 \mathrm{~A}} \mathrm{Rs}$. prefrontal pyramidal neurons (Willins et al., 1997; Martín-Ruiz et al., 2001; Santana et al., 2004), and stimulation of 5- $\mathrm{HT}_{2 \mathrm{~A} / 2 \mathrm{C}} \mathrm{Rs}$ with the agonist and hallucinogen DOI impairs synchronization of slow waves in the PFC, an effect that is reversed by the selective 5- $\mathrm{HT}_{2 \mathrm{~A}} \mathrm{R}$ antagonist M100907 (Celada et al., 2008). Remarkably, blockade of $5-\mathrm{HT}_{2 \mathrm{~A} / 2 \mathrm{C}}$ Rs by RIT, but not blockade of $5-\mathrm{HT}_{2 \mathrm{C}} \mathrm{Rs}$ by $\mathrm{SB}$, also desynchronizes slow waves by increasing UP-state potentials. Because $5-\mathrm{HT}_{2 \mathrm{~A}} \mathrm{Rs}$ are also expressed by GABAergic interneurons in the PFC (Santana et al., 2004; this study), a reduction in the activity of cortical interneurons such as "early" FSi with RIT would disinhibit pyramidal cells, possibly facilitating UP state initiation. Low density of 5- $\mathrm{HT}_{2 \mathrm{~A}}$ Rs is found in GABAergic interneurons of the DRN (Pompeiano et al., 1994; Fay and Kubin, 2000), so it is plausible that RIT indirectly disinhibits 5-HT neurons by inactivating local GABA inputs, further promoting the release of 5-HT in the PFC.

Thus, pharmacological stimulation or blockade of $5-\mathrm{HT}_{2 \mathrm{~A}} \mathrm{Rs}$ with DOI and RIT alter slow rhythms in the PFC, suggesting that a balanced activation of $5-\mathrm{HT}_{2 \mathrm{~A}} \mathrm{Rs}$ is critical for a stable synchronization of slow waves. $5-\mathrm{HT}_{2 \mathrm{~A}} \mathrm{Rs}$ may be altered in schizophrenia: atypical antipsychotics are potent $5-\mathrm{HT}_{2 \mathrm{~A}} \mathrm{R}$ antagonists whereas some hallucinogens are $5-\mathrm{HT}_{2 \mathrm{~A}} \mathrm{R}$ agonists (Meltzer, 1999; Meltzer and Huang, 2008). Interestingly, a reduction of slow-wave activity has been detected in patients with schizo- 
phrenia during sleep (Hoffmann et al., 2000). Our results, together with previous observations, suggest that a potential source of this decrease could be an unbalanced stimulation of cortical 5- $\mathrm{HT}_{2 \mathrm{~A}} \mathrm{Rs}$.

\section{Serotonin downregulates neuronal activity in the PFC through 5-HT ${ }_{1 \mathrm{~A}} \mathrm{Rs}$}

Serotonin predominantly (66\%) downregulates pyramidal cell activity in vivo via stimulation of $5-\mathrm{HT}_{1 \mathrm{~A}} \mathrm{Rs}$ (Puig et al., 2003, 2005 ). Similarly, the majority ( $\sim 61 \%$ ) of responses elicited in FSi by DRN stimulation are inhibitions. This agrees with a recent in vitro study reporting that 5-HT reduces GABA release from cortical FSi (Kruglikov and Rudy, 2008). The inhibitions have latencies ( $\sim 22 \mathrm{~ms})$ that are consistent with the conduction velocity of serotonergic axons, and are fully or partially blocked by WAY, indicating that they are mediated by $5-\mathrm{HT}_{1 \mathrm{~A}} \mathrm{Rs}$. The initial $5-\mathrm{HT}_{1 \mathrm{~A}} \mathrm{R}$-independent component of some of the inhibitions is possibly GABA-mediated, either by the proposed raphe-cortex GABAergic projection (Puig et al., 2005), or by intracortical inhibitory inputs.

Few FSi are activated by DRN stimulation $(\sim 10 \%)$, challenging the pharmacological characterization. The involvement of $5-\mathrm{HT}_{2 \mathrm{~A}} \mathrm{Rs}$, and not $5-\mathrm{HT}_{2 \mathrm{C}} \mathrm{Rs}$, is suggested by the blockade of the activations by RIT and the lack of effect of SB. Moreover, the delay of the activations $(\sim 77 \mathrm{~ms})$ is similar to that of $5-\mathrm{HT}_{2 \mathrm{~A}} \mathrm{R}-$ mediated excitations in pyramidal neurons ( $\sim 71 \mathrm{~ms}$; AmargósBosch et al., 2004; Puig et al., 2005), and too long for either glutamatergic- $(\sim 10 \mathrm{~ms})$ or $5-\mathrm{HT}_{3} \mathrm{R}-(\sim 36 \mathrm{~ms})$ mediated excitatory responses (Puig et al., 2004, 2008; Varga et al., 2009).

ISH experiments support the electrophysiological data by showing that FSi in the MOs express $5-\mathrm{HT}_{1 \mathrm{~A}} \mathrm{Rs}$ and $5-\mathrm{HT}_{2 \mathrm{~A}} \mathrm{Rs}$, but not $5-\mathrm{HT}_{2 \mathrm{C}} \mathrm{Rs}$. In fact, most $5-\mathrm{HT}_{2 \mathrm{C}} \mathrm{R}$-expressing cells are excitatory, in disagreement with a recent study showing that $\sim 25 \%$ of FSi in the PFC are immunopositive for $5-\mathrm{HT}_{2 \mathrm{C}} \mathrm{Rs}$ (Liu et al., 2007). The ISH also shows that there are two distinct populations of FSi expressing $5-\mathrm{HT}_{1 \mathrm{~A}} \mathrm{Rs}$ and $5-\mathrm{HT}_{2 \mathrm{~A}} \mathrm{Rs}$. There is a clear disparity between the percentage of PV-5- $\mathrm{HT}_{1 \mathrm{~A}} \mathrm{R}$ mRNAcoexpressing cells $(\sim 36 \%)$ and the inhibitory responses evoked by DRN stimulations $(\sim 61 \%)$. Two reasons may account for this: (1) limited detection levels for the $5-\mathrm{HT}_{1 \mathrm{~A}} \mathrm{R}$ probes, and (2) the fact that many FSi recorded during SWS-like states display an "early" pattern, and "early" FSi are proportionally more inhibited by 5 -HT than "late" FSi. We hypothesize that during alertness more "late" FSi are active, so the number of FSi excited (5$\mathrm{HT}_{2 \mathrm{~A}} \mathrm{R}$-expressing) and inhibited (5- $\mathrm{HT}_{1 \mathrm{~A}} \mathrm{R}$-expressing) by 5-HT might be more balanced (Table 1). Nevertheless, our results differ with a previous study reporting a very high expression of 5- $\mathrm{HT}_{1 \mathrm{~A}} \mathrm{R}$ immunoreactivity in PV-containing neurons (85-99\%; Aznar et al., 2003).

\section{Dual action of serotonin on pyramidal networks of the PFC}

UP and DOWN states reflect alternating periods of membrane depolarization and hyperpolarization of large neuronal ensembles (Contreras and Steriade, 1995; Mukovski et al., 2007). In this study we show that DRN stimulations increase UP-state potentials in the LFPs, suggesting that 5-HT induces an overall membrane depolarization in many cortical pyramidal neurons. However, 5-HT exerts a potent inhibitory modulation of pyramidal activity (Puig et al., 2003, 2005). A plausible explanation for this paradox is the distinct distribution of $5-\mathrm{HT}_{1 \mathrm{~A}} \mathrm{Rs}$ and 5- $\mathrm{HT}_{2 \mathrm{~A}} \mathrm{Rs}$ within pyramidal neurons: $5-\mathrm{HT}_{1 \mathrm{~A}} \mathrm{Rs}$ are densely located on the axon initial segment (DeFelipe et al., 2001), where they downregulate action potential generation; in contrast,
5- $\mathrm{HT}_{2 \mathrm{~A}} \mathrm{Rs}$ are abundant on the apical dendrites (Jakab and Goldman-Rakic, 1998), where they increase EPSCs (Aghajanian and Marek, 1999). Thus, 5- $\mathrm{HT}_{1 \mathrm{~A}} \mathrm{Rs}$ are located downstream of $5-\mathrm{HT}_{2 \mathrm{~A}} \mathrm{Rs}$ in the process of spike generation, explaining why the overall effect of 5-HT on cortical pyramidal activity is inhibitory despite many pyramidal neurons coexpress $5-\mathrm{HT}_{1 \mathrm{~A}} \mathrm{Rs}$ and 5- $\mathrm{HT}_{2 \mathrm{~A}}$ Rs (Amargós-Bosch et al., 2004). LFPs reflect the summation of postsynaptic potentials in dendrites and are independent of action potential generation, whereas spiking activity represents the results of local processing (Nielsen et al., 2006; Monosov et al., 2008). Our results suggest that 5-HT may play a dual action on cortical pyramidal networks by enhancing synaptic inputs through $5-\mathrm{HT}_{2 \mathrm{~A}} \mathrm{Rs}$ located on pyramidal dendrites, while downregulating spiking activity at the axon level through $5-\mathrm{HT}_{1 \mathrm{~A}} \mathrm{R}$ stimulation.

\section{Serotonin modulates gamma oscillations through 5-HT ${ }_{1 \mathrm{~A}} \mathrm{R}$ - and 5- $\mathrm{HT}_{2 \mathrm{~A}} \mathrm{R}$-expressing FSi}

Networks of FSi generate gamma oscillations (Whittington and Traub, 2003; Bartos et al., 2007), and the manipulation of FSi activity in vivo modulates the amplitude of gamma waves (Cardin et al., 2009). Here we show that many FSi express $5-\mathrm{HT}_{1 \mathrm{~A}} \mathrm{Rs}$ and $5-\mathrm{HT}_{2 \mathrm{~A}} \mathrm{Rs}$, providing a substrate by which 5 - $\mathrm{HT}$ can regulate gamma oscillations.

WAY increases both the amplitude of gamma oscillations and the discharge rate of $5-\mathrm{HT}_{1 \mathrm{~A}} \mathrm{R}$-expressing $\mathrm{FSi}$, while sharpening the synchronization of these neurons to gamma cycles. Thus, 5-HT may directly regulate the amplitude of gamma waves through 5-HT ${ }_{1 \mathrm{~A}} \mathrm{R}$-expressing FSi. WAY also increases pyramidal activity (Amargós-Bosch et al., 2004), promoting the interplay between the pyramidal and the FSi networks to further enhance gamma oscillations. Moreover, RIT, but not SB, reduces the amplitude of gamma waves and decouples some putative $5-\mathrm{HT}_{2 \mathrm{~A}} \mathrm{R}$ expressing FSi from gamma cycles. This effect, combined with a downregulation of pyramidal excitatory currents, may desynchronize the FSi network. A direct serotonergic regulation of the amplitude of gamma oscillations by $5-\mathrm{HT}_{1 \mathrm{~A}} \mathrm{R}$ - and $5-\mathrm{HT}_{2 \mathrm{~A}} \mathrm{R}$ expressing FSi is also suggested by the fact that very few FSi express $5-\mathrm{HT}_{2 \mathrm{C}} \mathrm{Rs}$, and that blockade of $5-\mathrm{HT}_{2 \mathrm{C}} \mathrm{Rs}$ by $\mathrm{SB}$ does not modify the amplitude of gamma waves.

Importantly, the administration of the antagonists was systemic, so we cannot disregard the possibility that these effects originate in subcortical structures. However, this is unlikely because gamma oscillations are generated locally in the cortex (Steriade et al., 1996; Sirota et al., 2008), where levels of postsynaptic 5- $\mathrm{HT}_{1 \mathrm{~A}}$ Rs and 5- $\mathrm{HT}_{2 \mathrm{~A}}$ Rs are very high (Pompeiano et al., 1992, 1994).

Because most FSi and pyramidal neurons in the PFC are inhibited by DRN stimulation during SWS-like states, overall 5-HT may downregulate cortical gamma oscillations. This is precisely what we observe after high-frequency stimulation of the DRN. Yet, during waking-like states a larger proportion of FSi is activated. This suggests that 5 -HT increases the spiking of many FSi during alertness, balancing the activation of $5-\mathrm{HT}_{1 \mathrm{~A}} \mathrm{R}$ - and $5-\mathrm{HT}_{2 \mathrm{~A}} \mathrm{R}$-expressing FSi, and allowing the serotonergic system to finely tune the amplitude of gamma oscillations during cognitive tasks.

\section{References}

Aghajanian GK, Marek GJ (1999) Serotonin, via 5-HT2a receptors, increases EPSCs in layer V pyramidal cells of prefrontal cortex by an asynchronous mode of glutamate release. Brain Res 825:161-171.

Amargós-Bosch M, Bortolozzi A, Puig MV, Serrats J, Adell A, Celada P, Toth 
M, Mengod G, Artigas F (2004) Co-expression and in vivo interaction of serotonin1 A and serotonin2A receptors in pyramidal neurons of prefrontal cortex. Cereb Cortex 14:281-299.

Aznar S, Qian Z, Shah R, Rahbek B, Knudsen GM (2003) The 5-HT1A serotonin receptor is located on calbindin- and parvalbumin-containing neurons in the rat brain. Brain Res 959:58-67.

Bartos M, Vida I, Jonas P (2007) Synaptic mechanisms of synchronized gamma oscillations in inhibitory interneuron networks. Nat Rev Neurosci 8:45-56.

Başar E, Güntekin B (2008) A review of brain oscillations in cognitive disorders and the role of neurotransmitters. Brain Res 1235:172-193.

Boothman L, Raley J, Denk F, Hirani E, Sharp T (2006) In vivo evidence that 5-HT2C receptors inhibit 5-HT neuronal activity via a GABAergic mechanism. Br J Pharmacol 149:861-869.

Cardin JA, Carlén M, Meletis K, Knoblich U, Zhang F, Deisseroth K, Tsai LH, Moore CI (2009) Driving fast-spiking cells induces gamma rhythm and controls sensory responses. Nature 459:663-667.

Celada P, Puig MV, Casanovas JM, Guillazo G, Artigas F (2001) Control of dorsal raphe serotonergic neurons by the medial prefrontal cortex: involvement of serotonin-1A, GABA $A_{A}$, and glutamate receptors. J Neurosci 21:9917-9929.

Celada P, Puig MV, Díaz-Mataix L, Artigas F (2008) The hallucinogen DOI reduces low-frequency oscillations in rat prefrontal cortex: reversal by antipsychotic drugs. Biol Psychiatry 64:392-400.

Cho RY, Konecky RO, Carter CS (2006) Impairments in frontal cortical gamma synchrony and cognitive control in schizophrenia. Proc Natl Acad Sci U S A 103:19878-19883.

Contreras D, Steriade M (1995) Cellular basis of EEG slow rhythms: a study of dynamic corticothalamic relationships. J Neurosci 15:604-622.

de Almeida J, Mengod G (2007) Quantitative analysis of glutamatergic and GABAergic neurons expressing 5-HT2A receptors in human and monkey prefrontal cortex. J Neurochem 103:475-486.

DeFelipe J, Arellano JI, Gómez A, Azmitia EC, Muñoz A (2001) Pyramidal cell axons show a local specialization for GABA and 5-HT inputs in monkey and human cerebral cortex. J Comp Neurol 433:148-155.

Dringenberg HC, Vanderwolf CH (1997) Neocortical activation: modulation by multiple pathways acting on central cholinergic and serotonergic systems. Exp Brain Res 116:160-174.

Elvevåg B, Goldberg TE (2000) Cognitive impairment in schizophrenia is the core of the disorder. Crit Rev Neurobiol 14:1-21.

Fay R, Kubin L (2000) Pontomedullary distribution of 5- $\mathrm{HT}_{2 \mathrm{~A}}$ receptor-like protein in the rat. J Comp Neurol 418:323-345.

Gabbott PLA, Warner TA, Jays PRL, Salway P, Busby SJ (2005) Prefrontal cortex in the rat: projections to subcortical autonomic, motor, and limbic centers. J Comp Neurol 492:145-177.

Gartside SE, Hajós-Korcsok E, Bagdy E, Hársing LG Jr, Sharp T, Hajós M (2000) Neurochemical and electrophysiological studies on the functional significance of burst firing in serotonergic neurons. Neuroscience 98:295-300.

Gras C, Herzog E, Bellenchi GC, Bernard V, Ravassard P, Pohl M, Gasnier B, Giros B, El Mestikawy S (2002) A third vesicular glutamate transporter expressed by cholinergic and serotoninergic neurons. J Neurosci 22:5442-5451.

Hajós M, Richards CD, Székely AD, Sharp T (1998) An electrophysiological and neuroanatomical study of the medial prefrontal cortical projection to the midbrain raphe nuclei in the rat. Neuroscience 87:95-108.

Hajós M, Gartside SE, Varga V, Sharp T (2003) In vivo inhibition of neuronal activity in the rat ventromedial prefrontal cortex by midbrain-raphe nuclei: role of 5-HT1A receptors. Neuropharmacology 45:72-81.

Harder JA, Ridley RM (2000) The 5-HT $1 \mathrm{~A}$ antagonist, WAY 100 635, alleviates cognitive impairments induced by dizocilpine (MK-801) in monkeys. Neuropharmacology 39:547-552.

Harvey PD, Bowie CR, Friedman JI (2001) Cognition in schizophrenia. Curr Psychiatry Rep 3:423-428.

Heisler LK, Chu HM, Brennan TJ, Danao JA, Bajwa P, Parsons LH, Tecott LH (1998) Elevated anxiety and antidepressant-like responses in serotonin receptor 5-HT ${ }_{1 \mathrm{~A}}$ mutant mice. Proc Natl Acad Sci U S A 95:15049-15054.

Hoffmann R, Hendrickse W, Rush AJ, Armitage R (2000) Slow-wave activity during non-REM sleep in men with schizophrenia and major depressive disorders. Psychiatry Res 95:215-225.

Hoover WB, Vertes RP (2007) Anatomical analysis of afferent projections to the medial prefrontal cortex in the rat. Brain Struct Funct 212:149-179.
Howard MW, Rizzuto DS, Caplan JB, Madsen JR, Lisman J, AschenbrennerScheibe R, Schulze-Bonhage A, Kahana MJ (2003) Gamma oscillations correlate with working memory load in humans. Cereb Cortex 13:13691374.

Hoyer D (1988) Molecular pharmacology and biology of 5-HT1C receptors. Trends Pharmacol Sci 9:89-94.

Jackson J, Bland BH, Antle MC (2009) Nonserotonergic projection neurons in the midbrain raphe nuclei contain the vesicular glutamate transporter VGLUT3. Synapse 63:31-41.

Jakab RL, Goldman-Rakic PS (1998) 5-Hydroxytryptamine(2A) serotonin receptors in the primate cerebral cortex: possible site of action of hallucinogenic and antipsychotic drugs in pyramidal cell apical dendrites. Proc Natl Acad Sci U S A 95:735-740.

Jenck F, Moreau JL, Mutel V, Martin JR, Haefely WE (1993) Evidence for a role of 5-HT1C receptors in the antiserotonergic properties of some antidepressant drugs. Eur J Pharmacol 231:223-229.

Kawaguchi Y, Kubota Y (1997) GABAergic cell subtypes and their synaptic connections in rat frontal cortex. Cereb Cortex 7:476-486.

Kennett GA, Wood MD, Bright F, Trail B, Riley G, Holland V, Avenell KY, Stean T, Upton N, Bromidge S, Forbes IT, Brown AM, Middlemiss DN, Blackburn TP (1997) SB 242084, a selective and brain penetrant 5-HT2C receptor antagonist. Neuropharmacology 36:609-620.

Kruglikov I, Rudy B (2008) Perisomatic GABA release and thalamocortical integration onto neocortical excitatory cells are regulated by neuromodulators. Neuron 58:911-924.

Lewis DA, Hashimoto T, Volk DW (2005) Cortical inhibitory neurons and schizophrenia. Nat Rev Neurosci 6:312-324.

Liu S, Bubar MJ, Lanfranco MF, Hillman GR, Cunningham KA (2007) Serotonin2C receptor localization in GABA neurons of the rat medial prefrontal cortex: implications for understanding the neurobiology of addiction. Neuroscience 146:1677-1688.

Marshall L, Helgadóttir H, Mölle M, Born J (2006) Boosting slow oscillations during sleep potentiates memory. Nature 444:610-613.

Martín-Ruiz R, Puig MV, Celada P, Shapiro DA, Roth BL, Mengod G, Artigas F (2001) Control of serotonergic function in medial prefrontal cortex by serotonin-2A receptors through a glutamate-dependent mechanism. J Neurosci 21:9856-9866.

McQuade R, Sharp T (1995) Release of cerebral 5-hydroxytryptamine evoked by electrical stimulation of the dorsal and median raphe nuclei: effect of a neurotoxic amphetamine. Neuroscience 68:1079-1088.

Meltzer HY (1999) The role of serotonin in antipsychotic drug action. Neuropsychopharmacology 21:S106-S115.

Meltzer HY, Huang M (2008) In vivo actions of atypical antipsychotic drug on serotonergic and dopaminergic systems. Prog Brain Res 172:177-197.

Miller EK, Cohen JD (2001) An integrative theory of prefrontal cortex function. Annu Rev Neurosci 24:167-202.

Monosov IE, Trageser JC, Thompson KG (2008) Measurements of simultaneously recorded spiking activity and local field potentials suggest that spatial selection emerges in the frontal eye field. Neuron 57:614-625.

Mukovski M, Chauvette S, Timofeev I, Volgushev M (2007) Detection of active and silent states in neocortical neurons from the field potential signal during slow-wave sleep. Cereb Cortex 17:400-414.

Nielsen KJ, Logothetis NK, Rainer G (2006) Dissociation between local field potentials and spiking activity in macaque inferior temporal cortex reveals diagnosticity-based encoding of complex objects. J Neurosci 26:9639-9645.

Parks CL, Robinson PS, Sibille E, Shenk T, Toth M (1998) Increased anxiety of mice lacking the serotonin(1a) receptor. Proc Natl Acad Sci U S A 95:10734-10739.

Pinault D (1996) A novel single-cell staining procedure performed in vivo under electrophysiological control: morpho-functional features of juxtacellularly labeled thalamic cells and other central neurons with biocytin or neurobiotin. J Neurosci Methods 65:113-136.

Pompeiano M, Palacios JM, Mengod G (1992) Distribution and cellular localization of mRNA coding for 5-HT1A receptor in the rat brain: correlation with receptor binding. J Neurosci 12:440-453.

Pompeiano M, Palacios JM, Mengod G (1994) Distribution of the serotonin 5-HT2 receptor family mRNAs: comparison between 5-HT2A and 5-HT2C receptors. Mol Brain Res 23:163-178.

Portas CM, Bjorvatn B, Ursin R (2000) Serotonin and the sleep/wake cycle: special emphasis on microdialysis studies. Prog Neurobiol 60:13-35.

Puig MV, Celada P, Díaz-Mataix L, Artigas F (2003) In vivo modulation of 
the activity of pyramidal neurons in the rat medial prefrontal cortex by 5-HT2A receptors: relationship to thalamocortical afferents. Cereb Cortex 13:870-882.

Puig MV, Santana N, Celada P, Mengod G, Artigas F (2004) In vivo excitation of GABA interneurons in the medial prefrontal cortex through 5-HT3 receptors. Cereb Cortex 14:1365-1375.

Puig MV, Artigas F, Celada P (2005) Modulation of the activity of pyramidal neurons in rat prefrontal cortex by raphe stimulation in vivo: involvement of serotonin and GABA. Cereb Cortex 15:1-14.

Puig MV, Ushimaru M, Kawaguchi Y (2008) Two distinct activity patterns of fast-spiking interneurons during neocortical UP states. Proc Natl Acad Sci U S A 105:8428-8433.

Robbins TW (2005) Chemistry of the mind: neurochemical modulation of prefrontal cortical function. J Comp Neurol 493:140-146.

Santana N, Bortolozzi A, Serrats J, Mengod G, Artigas F (2004) Expression of serotonin $1 \mathrm{~A}$ and serotonin2A receptors in pyramidal and GABAergic neurons of the rat prefrontal cortex. Cereb Cortex 14:1100-1109.

Singer W (1999) Neuronal synchrony: a versatile code for the definition of relations? Neuron 24:49-65.

Sirota A, Montgomery S, Fujisawa S, Isomura Y, Zugaro M, Buzsáki G (2008) Entrainment of neocortical neurons and gamma oscillations by the hippocampal theta rhythm. Neuron 60:683-697.

Spencer KM, Nestor PG, Niznikiewicz MA, Salisbury DF, Shenton ME, McCarley RW (2003) Abnormal neural synchrony in schizophrenia. J Neurosci 23:7407-7411.

Steriade M, Nuñez A, Amzica F (1993) A novel slow ( $<1 \mathrm{~Hz}$ ) oscillation of neocortical neurons in vivo: depolarizing and hyperpolarizing components. J Neurosci 13:3252-3265.

Steriade M, Amzica F, Contreras D (1996) Synchronization of fast (30-40 $\mathrm{Hz})$ spontaneous cortical rhythms during brain activation. J Neurosci 16:392-417.
Steriade M, Timofeev I, Grenier F (2001) Natural waking and sleep states: a view from inside neocortical neurons. J Neurophysiol 85:1969-1985.

Stickgold R (2005) Sleep-dependent memory consolidation. Nature 437: 1272-1278.

Uematsu M, Hirai Y, Karube F, Ebihara S, Kato M, Abe K, Obata K, Yoshida S, Hirabayashi M, Yanagawa Y, Kawaguchi Y (2008) Quantitative chemical composition of cortical GABAergic neurons revealed in transgenic venus-expressing rats. Cereb Cortex 18:315-330.

Ugedo L, Grenhoff J, Svensson TH (1989) Ritanserin, a 5-HT2 receptor antagonist, activates midbrain dopamine neurons by blocking serotonergic inhibition. Psychopharmacology 98:45-50.

Uhlhaas PJ, Haenschel C, Nikolić D, Singer W (2008) The role of oscillations and synchrony in cortical networks and their putative relevance for the pathophysiology of schizophrenia. Schizophr Bull 34:927-943.

Varga V, Losonczy A, Zemelman BV, Borhegyi Z, Nyiri G, Domonkos A, Hangya B, Holderith N, Magee JC, Freund TF (2009) Fast synaptic subcortical control of hippocampal circuits. Science 326:449-453.

Ward LM (2003) Synchronous neural oscillations and cognitive processes. Trends Cogn Sci 7:553-559.

Watakabe A, Ichinohe N, Ohsawa S, Hashikawa T, Komatsu Y, Rockland KS, Yamamori T (2007) Comparative analysis of layer-specific genes in mammalian neocortex. Cereb Cortex 17:1918-1933.

Whittington MA, Traub RD (2003) Interneuron diversity series: inhibitory interneurons and network oscillations in vitro. Trends Neurosci 26:676-682.

Williams GV, Rao SG, Goldman-Rakic PS (2002) The physiological role of 5-HT2A receptors in working memory. J Neurosci 22:2843-2854.

Willins DL, Deutch AY, Roth BL (1997) Serotonin 5- $\mathrm{HT}_{2 \mathrm{~A}}$ receptors are expressed on pyramidal cells and interneurons in the rat cortex. Synapse 27:79-82.

Zar JH (1999) Biostatistical analysis. Englewood Cliffs, NJ: Prentice Hall. 